\title{
Improvement of Drought Tolerance in Rice (Oryza sativa L.): Genetics, Genomic Tools, and the WRKY Gene Family
}

\author{
Mahbod Sahebi $\left(\mathbb{D},{ }^{1}\right.$ Mohamed M. Hanafi $\mathbb{D}^{1,},{ }^{1,2,3}$ M. Y. Rafii $\left(\mathbb{D},{ }^{1}\right.$ T. M. M. Mahmud, \\ Parisa Azizi $\mathbb{D}^{2}{ }^{2}$ Mohamad Osman, ${ }^{4}$ Rambod Abiri $\left(\mathbb{D},{ }^{5}\right.$ Sima Taheri, ${ }^{4}$ Nahid Kalhori, ${ }^{6}$ \\ M. Shabanimofrad, ${ }^{1}$ Gous Miah, ${ }^{1}$ and Narges Atabaki ${ }^{7}$ \\ ${ }^{1}$ Laboratory of Climate-Smart Food Crop Production, Institute of Tropical Agriculture and Food Security, Universiti Putra Malaysia, \\ 43400 Serdang, Selangor, Malaysia \\ ${ }^{2}$ Laboratory of Plantation Science and Technology, Institute of Plantation Studies, Universiti Putra Malaysia, 43400 Serdang, \\ Selangor, Malaysia \\ ${ }^{3}$ Department of Land Management, Faculty of Agriculture, Universiti Putra Malaysia, 43400 Serdang, Selangor, Malaysia \\ ${ }^{4}$ Department of Crop Science, Faculty of Agriculture, Universiti Putra Malaysia, 43400 Serdang, Selangor, Malaysia \\ ${ }^{5}$ Department of Biochemistry, Faculty of Biotechnology and Biomolecular Sciences, Universiti Putra Malaysia, \\ 43400 Serdang, Selangor, Malaysia \\ ${ }^{6}$ Department of Biology, Faculty of Science, Universiti Putra Malaysia, 43400 Serdang, Selangor, Malaysia \\ ${ }^{7}$ Iran Azad University of Tehran Science \& Reserach Branch, Hesarak, Tehran 1477893855, Iran
}

Correspondence should be addressed to Mahbod Sahebi; mahbod_sahebi@yahoo.com and Mohamed M. Hanafi; mmhanafi@upm.edu.my

Received 10 May 2018; Revised 14 June 2018; Accepted 5 July 2018; Published 7 August 2018

Academic Editor: Maxim Golovkin

Copyright (C) 2018 Mahbod Sahebi et al. This is an open access article distributed under the Creative Commons Attribution License, which permits unrestricted use, distribution, and reproduction in any medium, provided the original work is properly cited.

Drought tolerance is an important quantitative trait with multipart phenotypes that are often further complicated by plant phenology. Different types of environmental stresses, such as high irradiance, high temperatures, nutrient deficiencies, and toxicities, may challenge crops simultaneously; therefore, breeding for drought tolerance is very complicated. Interdisciplinary researchers have been attempting to dissect and comprehend the mechanisms of plant tolerance to drought stress using various methods; however, the limited success of molecular breeding and physiological approaches suggests that we rethink our strategies. Recent genetic techniques and genomics tools coupled with advances in breeding methodologies and precise phenotyping will likely reveal candidate genes and metabolic pathways underlying drought tolerance in crops. The WRKY transcription factors are involved in different biological processes in plant development. This zinc $(\mathrm{Zn})$ finger protein family, particularly members that respond to and mediate stress responses, is exclusively found in plants. A total of 89 WRKY genes in japonica and 97 WRKY genes in O. nivara (OnWRKY) have been identified and mapped onto individual chromosomes. To increase the drought tolerance of rice (Oryza sativa L.), research programs should address the problem using a multidisciplinary strategy, including the interaction of plant phenology and multiple stresses, and the combination of drought tolerance traits with different genetic and genomics approaches, such as microarrays, quantitative trait loci (QTLs), WRKY gene family members with roles in drought tolerance, and transgenic crops. This review discusses the newest advances in plant physiology for the exact phenotyping of plant responses to drought to update methods of analysing drought tolerance in rice. Finally, based on the physiological/morphological and molecular mechanisms found in resistant parent lines, a strategy is suggested to select a particular environment and adapt suitable germplasm to that environment.

\section{Introduction}

As sessile organisms, plants encounter a wide spectrum of adverse conditions in their environment. Water deficit is a widespread challenge to sustainable agriculture [1]. Recently, a considerable body of research has developed around the theme of plant feedback under drought conditions. Evidence suggests that various pathways, mechanisms, and structures 
are among the most important factors in plant responses to dehydration. Water stress includes both water deficit and low-osmotic stress: desiccation and dehydration or drying and drought. Depending on the response, drought and desiccation tolerance occur via various mechanisms in plants.

Although desiccation tolerance is rare, it occurs globally [2]. Desiccation tolerance is found in plants, microorganisms, animals, mosses, terrestrial microalgae, symbiotic fungi, cyanobacteria (photobionts), yeast, and bacteria [3]. Drought tolerance is defined as plant tolerance under the minimum level of moisture content in the cytoplasm when the water content constitutes $\sim 23 \%$ or $\sim 0.3 \mathrm{~g}$ of the fresh and dry tissue, respectively. Drought tolerance mechanisms, including morphological adaptations, physiological acclimation, and cellular adjustments, are controlled by genetic factors at different steps. Morphological adaptations include increased root thickness and length, waxy or/and thick leaf coverings, decreased leaf weight and size, smaller epithelial cells, delayed leaf senescence, and increased green leaf area. Physiological acclimation consists of the following: higher stomatal density and conductance; decreased transpiration rates; reduced and early asynchrony between female and male flowering and maturation; and better production, accumulation, assimilation, and seed and biomass yield partitioning. Finally, cellular adjustments for desiccation tolerance entail increased chlorophyll content, particle numbers, and harvest index and lower osmotic potential [4]. In drought and desiccation tolerance, the accumulation of different molecules, such as nonreducing disaccharides and oligosaccharides, solutes with equal osmotic potential and particular proteins and tends to fluctuate [5]. The biosynthesis and interaction of drought and desiccation tolerance-related molecules are vital processes in living organisms under stress [6]. To overcome drought stress, which leads to crop loss worldwide, access to efficient protocols for phenotyping and to exotic germplasm is necessary [7].

Rice is the main staple food for one-third of people worldwide [8], providing up to $80 \%$ of these individuals' daily calories [9]. However, rice is considered one of the most drought-susceptible plants due to its small root system, thin cuticular wax, and swift stomatal closure [10]. Reportedly, nearly 23 million hectares of rain-fed rice face drought stress [11]. Genetic variations in the rice genes responsible for drought tolerance have been revealed via the screening and characterization of rice germplasm at different molecular, genetic, and morphological levels while under drought stress [12]. Hence, it may be possible to neutralize drought stress in rice in the future by developing drought-tolerant varieties.

Early senescence as a consequence of drought stress leads to an array of changes in many rice traits; tillering, leaf expansion, and midday photosynthesis are suppressed by drought stress because of early senescence [10]. Accumulation of osmolytes and organic acids, a reduction in photosynthetic efficiency, and changes in carbohydrate metabolism are the typical biochemical and physiological drought tolerance responses in rice [13]. In rice, reactive oxygen species (ROS) formation in various cellular compartments, such as mitochondria, peroxisomes, and chloroplasts, is an inevitable result of water shortage [14]. Overall, drought tolerance is a multifunctional output of numerous molecular, morphological, and biochemical characters. Although the mechanisms by which rice adapts to drought stress have been studied extensively, collectively, these data can also help understand the mechanism of the drought response and improve drought tolerance in rice [15]. Due to the availability of genomewide molecular markers, genome sequence information, and inexpensive genotyping platforms in rice, it is currently possible to routinely apply marker-assisted breeding techniques to improve rice grain yield under drought stress. Moreover, different functional databases and genomic resources for rice, as well as the latest omics advances, have facilitated the characterization of genes and pathways involved in drought tolerance that help in candidate gene identification and allele mining [12]. To this end, the current review focuses on reported work on mechanisms and some effects of drought stress on rice yield, as well as management strategies to overcome the effects of drought on rice.

\section{Quantitative Trait Loci for Drought Tolerance in Rice}

The drought tolerance mechanism is complex, influenced by variations in plant phenology and controlled by several quantitative trait loci (QTLs) [16]. The plant response is complex and difficult to understand unless a thorough study of the genetic and physiological bases of these responses is conducted. Neither modern genetics nor traditional breeding can effectively improve the drought tolerance of crop plants if the molecular mechanisms correlated with seed yield stability are not well understood [17]. Advances in systematic plant genomics, phenotyping, and plant physiology lead to new discoveries in crop drought tolerance. Hence, crop breeders will be able to increase crop yields using the latest gene network information and tools for plant improvement [18]. As improving plant physiology enhances our knowledge of the complex drought tolerance network and its relation with different traits, successful genomics and molecular biology approaches and increased selection efficiency will result in the identification of candidate QTLs and genes related to these traits. Molecular breeding approaches can be used to exploit QTLs for crop improvement; thus, candidate genes are the main targets for genetic engineering and the production of transgenic lines [19].

The identification of the candidate genes responsible for plant tolerance under different abiotic stresses, along with the use of the most suitable promoters associated with these events, is essential to develop transgenic crops with enhanced drought stress tolerance [19]. Although genetic engineering approaches involve costly regulatory procedures and negative public perceptions of biosafety, "molecular breeding" and "Induced Local Lesions in Genome" (TILLING) products are widely accepted [19]. The QTLs are ordinarily part of linkage mapping or linkage analysis-based QTL mapping [20]. Traditional mapping of QTLs involves mapping populations in which traits correlated with drought tolerance are segregating; identifying polymorphic markers; genotyping the mapping populations via polymorphic markers; constructing genetic maps; accurately phenotyping based on 
TABLE 1: The QTLs identified for drought tolerance-related traits in rice.

\begin{tabular}{|c|c|c|c|c|}
\hline Traits & Number of QTLs & $\begin{array}{l}\text { Chromosome/linkage } \\
\text { group }\end{array}$ & $\begin{array}{c}\text { Explained Phenotypic variation } \\
(\%)\end{array}$ & Reference \\
\hline Osmotic adjustment & $1\left(O A_{70}\right)$ & 8 & Major & {$[21]$} \\
\hline Drought avoidance & 17 & All except 9 & $4.4-25.6$ & {$[22]$} \\
\hline Root traits & 18 & All chromosomes & $1.2-18.5$ & [23] \\
\hline Root and related traits & 42 & All chromosomes & $6.0-24.4$ & {$[24]$} \\
\hline $\begin{array}{l}\text { Water stress indicators, phenology and } \\
\text { production traits }\end{array}$ & 47 & All except 5 & $5.0-59.0$ & {$[25]$} \\
\hline Grain yield and other agronomic traits & 77 & All except 12 & $7.5-55.7$ & {$[26]$} \\
\hline $\begin{array}{l}\text { Basal root thickness and 100-grain } \\
\text { weight }\end{array}$ & 2 & 4,6 & $20.6-33.4$ & {$[27]$} \\
\hline $\begin{array}{l}\text { Coleoptile length and drought } \\
\text { resistance index }\end{array}$ & 15 & All except $3,8,11$ & $4.9-22.7$ & {$[28]$} \\
\hline $\begin{array}{l}\text { Relative growth rate and specific water } \\
\text { use }\end{array}$ & 7 & $2,4,5,6,7,8$ & $10.0-22.0$ & [29] \\
\hline Grain yield & $1(q t l 12.1)$ & 12 & 51.0 & {$[30,31]$} \\
\hline Grain yield & 2 & 2,3 & $13.0-31.0$ & {$[32]$} \\
\hline Grain yield & $1(q D T Y 12.1)$ & 12 & 23.8 & [33] \\
\hline Grain yield & $1(q D T Y 3.2)$ & 3 & 23.4 & [34] \\
\hline Grain yield & 14 & All except 9, 11 & 13.3 & [35] \\
\hline Filled grain number per panicle & 23 & All except 12 & 33.3 & [35] \\
\hline Panicle number per plant & 14 & All except $1,3,8$ & - & [35] \\
\hline 1000-grain weight & 21 & All except 12 & 50.3 & [35] \\
\hline Grain yield (under drought stress) & $1(q D T Y 2.3)$ & 2 & 9.0 & {$[36]$} \\
\hline Grain yield (under drought stress) & $1(q D T Y 2.2)$ & 2 & 6.0 & {$[36]$} \\
\hline Grain yield & 4 & 3 & $18.8-31.8$ & [37] \\
\hline Physio-morphological & 9 & 4 & 36.8 & {$[38]$} \\
\hline Plant production & 24 & 1,6 & 14-20.9 & {$[38]$} \\
\hline Grain yield & 7 & $1,2,3,9,12$ & $31-77$ & {$[39]$} \\
\hline
\end{tabular}

drought tolerance-correlated traits; and finally, QTL mapping according to genotypic as well as phenotypic data. Several linkage mapping studies have been conducted on drought tolerance in different crops [16].

Because of inherent limitations associated with mapping populations, linkage analysis-based QTL mapping cannot offer detailed information about QTLs. These limitations include the following: the identified QTLs are commonly associated with large chromosomal segments or genomic regions due to insufficient time for recombination, inadequate phenotypic variation related to existing traits in the mapping population, and the segregation of different QTLs linked to the same traits in diverse mapping populations [89].

Linkage disequilibrium- (LD-) based association mapping (AM), which has been used in human genetics, has been suggested as a different QTL mapping approach to overcome some of these constraints in various crop species [90]. The association mapping (AM) method includes five steps: selecting various individual groups or panels from a natural germplasm/population pool; recording accurate phenotypic data on each group/panel; high-density sequencing of interesting candidate genes or the panel's genotyping markers; studying the level of genetic differentiation among panels within the particular population (population structure) and the relatedness coefficient between individual pairs within the population (kinship); and analysing the association mapping results according to data obtained on population structure, kinship, and the correlation of genotypic/haplotypic and phenotypic data. There are many advantages of the association mapping approach over biparental linkage mapping, as follows: higher resolution because of the utilization of all recombination events throughout the evolutionary history of a specific crop species; bypassing the development of a particular mapping population and the provision of a natural germplasm collection for a specific crop to reduce the required time for QTL mapping; using the same genotyping data and AM panel for mapping different traits mapping, making it a cost-effective approach; eliminating randomly recombinant inbred lines that express an insufficient agronomic type from the population's structure; and being able to sample and present many alleles per locus relative to linkage mapping (a survey of only two alleles). In summary, many QTLs related to drought tolerance in rice have been identified (Table 1). However, to date, only a few QTL studies on the impact of drought on grain quality have been reported; for example, a major QTL with an additive effect on grain yield 
under drought stress at the reproductive stage, qDTY1.1, was reported on rice chromosome 1 and flanked by RM11943 and RM431 in three populations: N22/Swarna, N22/IR64, and N22/MTU1010 [91]. Most QTLs have been identified based on a wide range of important traits, including (i) yield components, (ii) physiological responses, such as relative water content, osmotic potential, osmotic adjustment, leaf osmotic potential, flag leaf rolling index, chlorophyll contents, carbon isotope ratio, grain carbon isotope distinction, water-soluble carbohydrates, and (iii) root traits.

Several important mapped QTLs, as well as major genes related to abiotic stress tolerance, such as drought tolerance in rice and other crops, are available at (http://www.plantstress.com/biotech/index.asp?Flag=1). The QTLs identified for drought traits can only represent a small portion of phenotypic variation in crops. Thus, their direct use in marker-assisted selection (MAS) in breeding programmes is not sufficiently effective.

2.1. Analysis of QTLs Using Mathematical Models. Mathematical models in biology facilitate the understanding of yield efficiency as a multipart trait during drought. The procedure involves separating the phenotypes of the plants and their responses to environmental factors into fundamental and simple responses [92]. Modelling has been successfully used for leaf growth in maize [93]. Ecophysiological models and the precise measurement of environmental variables may address the problems posed by nonstable QTLs under different environmental conditions.

Combining ecophysiological models with QTL analysis predicts phenotypes that result from allelic combinations in each model. In this method, the QTLs related to a welldefined function and theories about the function of the gene underlying the QTL are expected to be more precise, and the number of candidate genes is lower than in conventional QTL mapping. Moreover, by using this approach, the reaction of a plant to a given environment can be predicted based on regulated gene networks [94]. Different pathway and network models can be developed using omics datasets that are activated in certain genotypes in response to drought. Models of the relationships between particular pathways and routes of the physiological responses to drought can be built directly using network information. The QTL cloning based on identified candidate genes will occur by comparing QTLs and gene regulatory networks for each parameter underlying the models. If all possible molecular and physiological aspects of a plant with the same germplasm in a particular drought situation are studied well, the phenotypes can be separated from the genes and the mechanisms, and suitable models can be built based on different allelic combinations.

2.2. Towards the Positional Cloning of QTLs Responsible for Drought Tolerance. In general, QTLs identified by linkage mapping-based methods are located in 10 to $20 \mathrm{cM}$ intervals, which have low resolution. Additionally, the interval of the QTL may span several candidate genes with causal influences on the trait. The positional cloning of QTLs has been undertaken in many crop species to identify casual genes [95]. Four main steps are involved in the cloning of QTLs: (i) restricting the region of the QTL using a mapping population, (ii) identifying a contig that spans the QTL region by screening for closely associated molecular markers in a very large insert library (e.g., a bacterial artificial chromosome library), (iii) sequencing the contig and identifying candidate genes, and (iv) confirming the candidate gene's effects on the phenotype. There are many reports on the cloning of QTLs related to different traits [96], but few address the cloning of QTLs linked to drought tolerance. For example, Vgtl, a flowering time QTL related to drought stress, was cloned in maize [96]; it showed an advantage in lowlands with warmer conditions by avoiding flowering at a phase when the plant would not have enough resources to reproduce successfully. Furthermore, Vgt1 affected the differentiation of maize varieties at different heights. A full subfamily $G$ (HvABCG31) transporter gene encoding an ATP-binding cassette and affecting water protection in leaves was recently cloned from barley and rice [97]. The fine mapping of a drought response can isolate a QTL region spanning many genes. Genes with an expression pattern associated with drought stress or encoding enzymes or proteins involved in drought stress-responsive metabolic pathways would be strong candidates for additional experiments. The largest changes in gene expression and protein or metabolite profiles may be directly identified from the mapping population. Synchronization between loci that control gene expression (eQTL), proteins (pQTL), and metabolites (mQTL) and yield and physiologically related loci allows inference of the biochemical progression underlying the physiological responses. In addition, colocalization of physiological QTLs and eQTLs for different traits can help identify candidate genes responsible for drought tolerance and facilitate positional cloning [98]. Integrating mapping populations and gene expression profiles of the lines using Affymetrix microarrays permits the identification of trans-eQTLs and delivers valuable data on the regulatory networks underlying different drought tolerance mechanisms. Classifying populations based on microarray analysis is an expensive method, but comparing the transpiration efficiency (high or low) of the progeny lines reduces the cost [99]. Modern genomics methods, such as next-generation sequencing (NGS) and mapping, promise to accelerate the cloning of QTLs associated with drought tolerance traits. Consequently, cloning QTLs related to drought tolerance offers an opportunity to confirm candidate genes. Finally, these genes may be used to develop transgenic staple crops as well as other crop species.

Regardless, marker-assisted breeding is not a perfect tool because it is effective only with major QTLs; hence, minor QTLs would be underrepresented in the selection process, resulting in missed genetic gains. Therefore, genomic selection (GS) has been suggested as a technique to show the collective impact of all alleles on polygenic traits. The GS method is advantageous because it includes the minor genes from traditional MAS [100]. This method is a form of MAS that reveals the genetic variances in each individual according to estimated breeding values from a genomic dataset. Compared to phenotypic selection, GS reduces the selection time for most traits by half per cycle in Arabidopsis, barley, and maize [101]. The GS is also a perfect method for use 
with altered environmental conditions and rare molecular markers [102]. The estimated precision of the breeding values of maize using GS has been reported to be 0.58 for grain yield and is predicted to be a better choice than other techniques considering the annual genetic gain of maize [101, 103].

\section{Identification of Candidate Drought Tolerance Genes in Model Plant Systems}

A wide range of candidate genes responsible for drought tolerance can be identified via important advances in model plant species. To date, the genomes of many model plants, as well as major plant species, have been sequenced [104]. Genome annotation, functional genomics, and molecular physiology studies have been conducted in several model and major crops to identify candidate genes involved in drought tolerance. These candidate genes include a large family of genes expressed under drought stress. Different proteins expressed by drought stress-associated candidate genes play significant roles in (i) cellular protection, such as osmotic adjustment, structural adaptation, repair, degradation, and detoxification and (ii) positive interactions with other proteins and transcription factors, such as protein kinases and bZIP, MYB, and DREB, which are involved in plant drought responses by regulating other responsive genes, such as those involved in cell protection, to cope with drought stress in plants. Identifying drought tolerance (DT) genes from different model plants and major crops is vital to understanding the functional basis of the DT mechanism and its downstream use, including validation via MAS through molecular breeding. The transcriptomic responses of some candidate DT genes identified from different plant species have been characterized and evaluated (Table 2).

Candidate genes should be validated via approaches, such as expression analysis, qRT-PCR, incorporation into QTL maps, linkage mapping, TILLING and allele mining, and applications of these approaches have been reviewed previously [105]. In recent years, many transcriptomic and functional genomic studies have been conducted to understand the stress mechanisms in different crop plants. One common approach that effectively isolates the candidate genes responsible for drought stress in drought-resistant genotypes is the generation of expressed sequence tags (ESTs) from cDNA libraries (normalized or nonnormalized) of tissues collected under drought. To date, many drought-responsive genes have been identified from several crop species (Table 2). Normalized cDNA libraries from rice seedlings led to the identification of many genes responsible for drought tolerance that were highly expressed under drought [106].

Transcriptional profiling is another approach to identify candidate genes and includes the differential gene expression analysis of plant tissues at different times after the onset of drought stress, as well as between drought-susceptible and drought-tolerant genotypes [107]. However, selection of the correct tissue type, tissue stage, and stress treatment (i.e., timing and intensity) are essential to determine the minimum drought conditions for isolating RNA for transcriptomics studies [108]. Near-isogenic lines (NILs) are the gold standard for genetic materials; they vary only in the specific trait among genotypes with diverse genetic backgrounds. Hence, a focus on NILs can provide high-confidence results that are very specific and are obtained from differentially expressed genes related to the target traits. Additionally, miRNAs have been demonstrated to be involved in drought responses and tolerance in many crop plants, such as soybean and rice, and can improve drought tolerance in plants [109].

There are various platforms that can be applied for transcriptional profiling, including PCR-based differential display PCR (DDRT-PCR) [110], cDNA-amplified fragment length polymorphism (cDNA-AFLP) [111], cDNA and suppression subtractive hybridization (SSH) [112], cDNA and oligonucleotide microarrays [113], and digital expression analysis based on EST counts [114]. Super-serial analysis of gene expression (super-SAGE) is another technique that can be successfully used in different crops under stress conditions [115]. As NGS technology provides precise digital and realtime analysis of sequence-based transcriptomes, other methods, such as microarrays, will likely be replaced with NGS in the near future. The use of NGS in gene expression analysis has led to novel techniques such as DeepSAGE [116], Digital Gene Expression-TAG (DGE-TAG) [117], and RNA-Seq [118].

The application of RNA-Seq, which involves NGS technology, has several advantages in the examination of transcriptome structure, such as the discovery of splice junctions and allele-specific expression [119], and NGS may provide high-throughput sequencing results directly from the RNA of stress-challenged tissues from different genotypes. The transcriptional profiling of drought-tolerant and droughtsensitive genotypes can identify candidate genes responsible for drought tolerance and, in combination with genetic/QTL maps, can act as "genic molecular markers" [120].

Several candidate genes identified via the above processes may be related to QTLs for drought tolerance traits. Therefore, a genetics and genomics method that allows the quantitative analysis of transcriptional profiling may isolate the expression QTLs (eQTLs) for drought tolerance traits [105]. Accordingly, if expressed QTLs are detected in the cis condition, the genes of interest based on molecular markers will act as "diagnostic markers" for the particular traits [121]. The results of our recent NGS (transcriptome) study on the screening and identification of novel genes involved in the most drought-resistant Malaysian rice variety identified thousands of up- and downregulated novel genes involved in more than one hundred different pathways (personal communication, Sahebi et al. 2016). Transcriptional profiling based on NGS technology will likely be used to identify candidate drought tolerance genes from major crop species and subsequently utilize them in molecular breeding or genetics and genomics.

\section{The Morphological Responses of Rice under Drought Stress}

Under drought stress, plants experience high rates of transpiration and lack sufficient water near the roots. Drought significantly impairs the growth, development, and yield of rice. When water is lacking, rice typically stops or slows down its growth [64]. Rice growth and development decrease as 
TABLE 2: Candidate genes related to drought stress of model plants and some of major crop species.

\begin{tabular}{|c|c|c|c|c|}
\hline Gene & Accession number & Plant species & Function/Plant trait & Reference \\
\hline $\mathrm{AAO} 3$ & AT2G27150 & Arabidopsis thaliana & $\begin{array}{l}\text { Stomatal Movement, Ion and Osmotic Homeostasis } \\
\text { Regulatory Proteins, ABA Biosynthesis, Hormone Signaling }\end{array}$ & {$[40]$} \\
\hline $\mathrm{ABCG} 22$ & AT5G06530 & Arabidopsis thaliana & Channels and Transporters & {$[41]$} \\
\hline $\mathrm{ABF} 3$ & AT4G34000 & Arabidopsis thaliana & Regulatory Proteins, Transcription Factors, bZIP & {$[42]$} \\
\hline $\mathrm{ABF} 4$ & AT3G19290 & Arabidopsis thaliana & Regulatory Proteins, Transcription Factors, bZIP & {$[42]$} \\
\hline ABCG40 & AT1G15520 & Arabidopsis thaliana & $\begin{array}{l}\text { Stomatal Movement, Ion and Osmotic Homeostasis, } \\
\text { Channels and Transporters, ABA Importer }\end{array}$ & {$[43]$} \\
\hline ABCG25 & AT1G71960 & Arabidopsis thaliana & $\begin{array}{l}\text { Stomatal Movement, Ion and Osmotic Homeostasis, } \\
\text { Channels and Transporters, ABA Exporter }\end{array}$ & {$[44]$} \\
\hline ABH1/CBP80 & AT2G13540 & Arabidopsis thaliana & Stomatal Movement, Ion and Osmotic Homeostasis & [45] \\
\hline ABO1/ELO1 & AT5G13680 & Arabidopsis thaliana & Stomatal Movement, Ion and Osmotic Homeostasis & [46] \\
\hline ADAP & AT1G16060 & Arabidopsis thaliana & Regulatory Proteins, Transcription Factors, AP2-Domain & [47] \\
\hline AGO1 & AT1G48410 & Arabidopsis thaliana & Regulatory Proteins, miRNA & [48] \\
\hline AHK1 & AT2G17820 & Arabidopsis thaliana & Regulatory Proteins, Signal Transduction, Protein Kinases & [49] \\
\hline AIRP1 & AT4G23450 & Arabidopsis thaliana & $\begin{array}{c}\text { Regulatory Proteins, Post-translational Modification, } \\
\text { Ubiquitin Ligases }\end{array}$ & {$[50]$} \\
\hline DREB2A & AT5G05410 & Arabidopsis thaliana & Regulatory Proteins, Transcription Factors, DREB & [51] \\
\hline HYL1 & AT1G09700 & Arabidopsis thaliana & Stomatal Movement, Ion and Osmotic Homeostasis & {$[52]$} \\
\hline LOS5 & AT1G16540 & Arabidopsis thaliana & Stomatal Movement, Ion and Osmotic Homeostasis & [53] \\
\hline AVP1 & AT1G15690 & Arabidopsis thaliana & Regulatory Proteins, Acid Anhydride Hydrolases & [54] \\
\hline NCED & AT3G14440 & Arabidopsis thaliana & $\begin{array}{l}\text { Stomatal Movement, Ion and Osmotic Homeostasis, } \\
\text { Hormone Signaling, ABA Biosynthesis }\end{array}$ & {$[55]$} \\
\hline GolS1 & AT2G47180 & Arabidopsis thaliana & $\begin{array}{l}\text { Detoxification, Osmolyte Production, Enzymes for Osmolyte } \\
\text { Biosynthesis }\end{array}$ & {$[56]$} \\
\hline GolS2 & AT1G56600 & Arabidopsis thaliana & $\begin{array}{l}\text { Detoxification, Osmolyte Production, Enzymes for Osmolyte } \\
\text { Biosynthesis }\end{array}$ & {$[56]$} \\
\hline AnnAt1 & AT1G35720 & Arabidopsis thaliana & Growth Control & {$[57]$} \\
\hline APX2 & AT1G07890 & Arabidopsis thaliana & Detoxification, Removal of ROS, Detoxification Signaling & {$[58]$} \\
\hline AREB1 & AT1G45249 & Arabidopsis thaliana & Regulatory Proteins, Transcription Factors, bZIP & [59] \\
\hline AtATL78 & AT1G49230 & Arabidopsis thaliana & Post-translational Modification, Ubiquitin Ligases & {$[60]$} \\
\hline AtBG1 & AT1G52400 & Arabidopsis thaliana & $\begin{array}{l}\text { Stomatal Movement, Ion and Osmotic Homeostasis, } \\
\text { Regulatory Proteins, Hormone and ABA Signaling }\end{array}$ & {$[61]$} \\
\hline ATHB6 & AT2G22430 & Arabidopsis thaliana & $\begin{array}{l}\text { Stomatal Movement, Ion and Osmotic Homeostasis, } \\
\text { Regulatory Proteins, Transcription Factors }\end{array}$ & {$[62]$} \\
\hline AtNF-YB1 & AT2G38880 & Arabidopsis thaliana & Regulatory Proteins, Transcription Factors, NF-Y & {$[62]$} \\
\hline AtrbohD & AT5G47910 & Arabidopsis thaliana & Stomatal Movement, Ion and Osmotic Homeostasis & {$[63]$} \\
\hline AtrbohF & AT1G64060 & Arabidopsis thaliana & Stomatal Movement, Ion and Osmotic Homeostasis & {$[63]$} \\
\hline OSM1/SYP61 & AT1G28490 & Arabidopsis thaliana & Stomatal Movement, Ion and Osmotic Homeostasis & {$[64]$} \\
\hline OST1/SRK2E & AT4G33950 & Arabidopsis thaliana & $\begin{array}{l}\text { Stomatal Movement, Ion and Osmotic Homeostasis, } \\
\text { Regulatory Proteins, Signal Transduction, Protein Kinases }\end{array}$ & {$[63]$} \\
\hline CBF4 & AT5G51990 & Arabidopsis thaliana & Regulatory Proteins, Transcription Factors, DREB & [65] \\
\hline MYC2 & AT1G32640 & Arabidopsis thaliana & Regulatory Proteins, Transcription Factors, MYC & {$[66]$} \\
\hline GORK & AT5G37500 & Arabidopsis thaliana & $\begin{array}{c}\text { Ion and Osmotic Homeostasis, Transporters, Ion Channels, } \\
\text { Cation Channel }\end{array}$ & {$[67]$} \\
\hline GCR1 & AT1G48270 & Arabidopsis thaliana & Stomatal Movement, Ion and Osmotic Homeostasis & {$[68]$} \\
\hline DREB1A/CBF3 & AT4G25480 & Arabidopsis thaliana & Regulatory Proteins, Transcription Factors, DREB & [69] \\
\hline СВР20 & AT5G44200 & Arabidopsis thaliana & $\begin{array}{l}\text { Stomatal Movement, Ion and Osmotic Homeostasis, } \\
\text { Regulatory Proteins, miRNA }\end{array}$ & {$[70]$} \\
\hline CLCc & AT5G49890 & Arabidopsis thaliana & $\begin{array}{l}\text { Ion and Osmotic Homeostasis, Channels and Transporters, } \\
\text { Ion and Anion Channel }\end{array}$ & {$[71]$} \\
\hline CML9 & AT3G51920 & Arabidopsis thaliana & Regulatory Proteins, Signal Transduction & {$[71]$} \\
\hline CPK21 & AT4G04720 & Arabidopsis thaliana & Regulatory Proteins, Signal Transduction, Protein Kinases & {$[72]$} \\
\hline
\end{tabular}


TABLe 2: Continued.

\begin{tabular}{|c|c|c|c|c|}
\hline Gene & Accession number & Plant species & Function/Plant trait & Reference \\
\hline CPK23 & AT4G04740 & Arabidopsis thaliana & Regulatory Proteins, Signal Transduction, Protein Kinases & [73] \\
\hline CYP707A1 & AT4G19230 & Arabidopsis thaliana & $\begin{array}{l}\text { Stomatal Movement, Ion and Osmotic Homeostasis, } \\
\text { Regulatory Proteins, Hormone Signaling, ABA Degradation }\end{array}$ & {$[74]$} \\
\hline CYP707A3 & AT5G45340 & Arabidopsis thaliana & $\begin{array}{l}\text { Stomatal Movement, Ion and Osmotic Homeostasis, } \\
\text { Regulatory Proteins, Hormone Signaling }\end{array}$ & {$[74]$} \\
\hline ERD1 & AT5G51070 & Arabidopsis thaliana & Detoxification, Proteases & [72] \\
\hline GPX3 & AT2G43350 & Arabidopsis thaliana & Detoxification, Removal of ROS, Detoxification Signaling & [73] \\
\hline HAB1 & AT1G72770 & Arabidopsis thaliana & $\begin{array}{c}\text { Ion and Osmotic Homeostasis, Regulatory Proteins, Signal } \\
\text { Transduction, Protein Phosphatases }\end{array}$ & [74] \\
\hline $\mathrm{HD} 2 \mathrm{C}$ & AT5G03740 & Arabidopsis thaliana & Regulatory Proteins, Histone Modification & {$[75]$} \\
\hline MYB2 & AT2G47190 & Arabidopsis thaliana & Regulatory Proteins, Transcription Factors, MYB & [66] \\
\hline MRP4 & AT2G47800 & Arabidopsis thaliana & $\begin{array}{l}\text { Stomatal Movement, Ion and Osmotic Homeostasis, } \\
\text { Channels and Transporters }\end{array}$ & {$[76]$} \\
\hline $\begin{array}{l}\text { SHINE1 } \\
\text { (SHN1/WIN1) }\end{array}$ & AT1G15360 & Arabidopsis thaliana & Regulatory Proteins, Transcription Factors, AP2-Domain & [77] \\
\hline SRK2C & AT1G78290 & Arabidopsis thaliana & Regulatory Proteins, Signal Transduction, Protein Kinases & [77] \\
\hline MYB60 & AT1G08810 & Arabidopsis thaliana & Regulatory Proteins, Transcription Factors, MYB & [78] \\
\hline MYB61 & AT1G09540 & Arabidopsis thaliana & Regulatory Proteins, Transcription Factors, MYB & [79] \\
\hline RPK1 & AT1G69270 & Arabidopsis thaliana & Regulatory Proteins, Signal Transduction, Protein Kinases & [80] \\
\hline RGS1 & AT3G26090 & Arabidopsis thaliana & $\begin{array}{c}\text { Growth Control, Root/Leaf Development, Signal } \\
\text { Transduction }\end{array}$ & {$[81]$} \\
\hline DOR & AT2G31470 & Arabidopsis thaliana & Stomatal Movement, Ion and Osmotic Homeostasis & [82] \\
\hline EDT1/HDG11 & AT1G73360 & Arabidopsis thaliana & $\begin{array}{c}\text { Growth Control, Root/Leaf Development, Regulatory } \\
\text { Proteins, Transcription Factors }\end{array}$ & [83] \\
\hline GPA1 & AT2G26300 & Arabidopsis thaliana & Stomatal Movement, Ion and Osmotic Homeostasis & [84] \\
\hline GTG1 & AT1G64990 & Arabidopsis thaliana & $\begin{array}{c}\text { Stomatal Movement, Ion and Osmotic Homeostasis, } \\
\text { Regulatory Proteins, Hormone Signaling }\end{array}$ & {$[84]$} \\
\hline SAD1 & AT5G48870 & Arabidopsis thaliana & Stomatal Movement, Ion and Osmotic Homeostasis & [85] \\
\hline HARDY & AT2G36450 & Arabidopsis thaliana & Regulatory Proteins, Transcription Factors, AP2-Domain & [78] \\
\hline OST2 & AT2G18960 & Arabidopsis thaliana & $\begin{array}{l}\text { Stomatal Movement, Ion and Osmotic Homeostasis, } \\
\text { Regulatory Proteins, Acid Anhydride Hydrolases }\end{array}$ & [78] \\
\hline PIP1;4 & AT4G00430 & Arabidopsis thaliana & $\begin{array}{c}\text { Ion and Osmotic Homeostasis, Channels and Transporters, } \\
\text { Water Channels }\end{array}$ & {$[81]$} \\
\hline PIP2;5 & AT3G54820 & Arabidopsis thaliana & $\begin{array}{c}\text { Ion and Osmotic Homeostasis, Channels and Transporters, } \\
\text { Water Channels }\end{array}$ & [81] \\
\hline KAT2 & AT4G18290 & Arabidopsis thaliana & $\begin{array}{l}\text { Ion and Osmotic Homeostasis, Channels and Transporters, } \\
\text { Ion Channels, Cation Channel }\end{array}$ & [82] \\
\hline MYB44 & AT5G67300 & Arabidopsis thaliana & Regulatory Proteins, Transcription Factors, MYB & [83] \\
\hline NFYA5 & AT1G54160 & Arabidopsis thaliana & Regulatory Proteins, Transcription Factors, NF-Y & {$[84]$} \\
\hline P5CS1 & AT2G39800 & Arabidopsis thaliana & $\begin{array}{c}\text { Detoxification, Osmolyte Production, Enzymes for Osmolyte } \\
\text { Biosynthesis }\end{array}$ & {$[86]$} \\
\hline SLAC1 & AT1G12480 & Arabidopsis thaliana & $\begin{array}{l}\text { Ion and Osmotic Homeostasis, Channels and Transporters, } \\
\text { Ion Channels, Anion Channel }\end{array}$ & {$[87]$} \\
\hline GTG2 & AT4G27630 & Arabidopsis thaliana & $\begin{array}{c}\text { Stomatal Movement, Ion and Osmotic Homeostasis, } \\
\text { Regulatory Proteins, Hormone Signaling }\end{array}$ & [88] \\
\hline OCP3 & AT5G11270 & Arabidopsis thaliana & Regulatory Proteins, Transcription Factors & [187] \\
\hline TPS1 & AT1G78580 & Arabidopsis thaliana & $\begin{array}{l}\text { Detoxification, Osmolyte Production, Functional Proteins, } \\
\text { Enzymes for Osmolyte Biosynthesis }\end{array}$ & [78] \\
\hline PYL9/RCAR1 & AT1G01360 & Arabidopsis thaliana & $\begin{array}{c}\text { Stomatal Movement, Ion and Osmotic Homeostasis, } \\
\text { Hormone Signaling }\end{array}$ & [82] \\
\hline SQE1 & AT1G58440 & Arabidopsis thaliana & Functional Proteins, Phospholipid Metabolism & [83] \\
\hline HDA19 & AT4G38130 & Arabidopsis thaliana & Regulatory Proteins, Histone Modification & {$[84]$} \\
\hline HDA6 & AT5G63110 & Arabidopsis thaliana & Regulatory Proteins, Histone Modification & {$[84]$} \\
\hline
\end{tabular}


TABLE 2: Continued.

\begin{tabular}{|c|c|c|c|c|}
\hline Gene & Accession number & Plant species & Function/Plant trait & Reference \\
\hline KAT2 & AT2G33150 & Arabidopsis thaliana & $\begin{array}{c}\text { Stomatal Movement, Ion and Osmotic Homeostasis, } \\
\text { Phospholipid Metabolism }\end{array}$ & [86] \\
\hline SLAH3 & AT5G24030 & Arabidopsis thaliana & $\begin{array}{l}\text { Ion and Osmotic Homeostasis, Channels and Transporters, } \\
\text { Ion Channels, Anion Channel }\end{array}$ & {$[87]$} \\
\hline PEPCK & AT4G37870 & Arabidopsis thaliana & Stomatal Movement, Ion and Osmotic Homeostasis & [88] \\
\hline MIR168A & AT4G19395 & Arabidopsis thaliana & Regulatory Proteins, miRNA & [47] \\
\hline FAR1 & AT4G15090 & Arabidopsis thaliana & Regulatory Proteins, Transcription Factors & [79] \\
\hline FHY3 & AT3G22170 & Arabidopsis thaliana & Regulatory Proteins, Transcription Factors & [79] \\
\hline AlSAP & LOC_Os07g07350 & Aeluropus littoralis & Regulatory Proteins, Transcription Factors, Zinc Fingers & [83] \\
\hline $\mathrm{CMO}$ & AT4G29890 & Atriplex hortensis & $\begin{array}{c}\text { Detoxification, Osmolyte Production, Enzymes for Osmolyte } \\
\text { Biosynthesis }\end{array}$ & [84] \\
\hline BnPIP1 & AT3G53420 & Brassica napus & $\begin{array}{l}\text { Ion and Osmotic Homeostasis; Functional Proteins; } \\
\text { Channels and Transporters; Water Channels }\end{array}$ & {$[86]$} \\
\hline BnPtdIns-PLC2 & AT3G08510 & Brassica napus & Functional Proteins; Phospholipid Metabolism & [87] \\
\hline CAP2 & Solyc05g052410 & Cicer arietinum & Regulatory Proteins, Transcription Factors, AP2-Domain & [88] \\
\hline SAMDC & Solyc05g010420 & Datura stramonium & $\begin{array}{c}\text { Detoxification, Osmolyte Production, Enzymes for Osmolyte } \\
\text { Biosynthesis }\end{array}$ & {$[80]$} \\
\hline GbRLK & LOC_Os04g56130 & $\begin{array}{l}\text { Gossypium } \\
\text { barbadense }\end{array}$ & Regulatory Proteins, Signal Transduction, Protein Kinases & [81] \\
\hline GhMKK1 & Solyc12g009020 & Gossypium hirsutum & Regulatory Proteins; Signal Transduction; Protein Kinases & [82] \\
\hline GmERF3 & Solyc06g063070 & Glycine max & Regulatory Proteins, Transcription Factors, AP2-Domain & [83] \\
\hline GsZFP1 & Glymalog44160 & Glycine soja & Regulatory Proteins, Transcription Factors, Zinc Fingers & [84] \\
\hline $\mathrm{CBF} 4$ & MLOC_54227 & Hordeum vulgare & Regulatory Proteins, Transcription Factors, DREB & [86] \\
\hline CDPK7 & LOC_Os03g03660 & Oryza sativa & Regulatory Proteins, Signal Transduction, Protein Kinases & [87] \\
\hline CIPK03 & LOC_Os07g48760 & Oryza sativa & Regulatory Proteins, Signal Transduction, Protein Kinases & {$[88]$} \\
\hline CIPK12 & LOC_Os01g55450 & Oryza sativa & Regulatory Proteins, Signal Transduction, Protein Kinases & {$[88]$} \\
\hline
\end{tabular}

a result of poor root growth; leaf surface traits are reduced, which impacts the radiation load on the leaf canopy, delays or reduces the rate of normal crop senescence as maturity is approached, and inhibits stem reserves [122]. Many studies have reported an array of early morphological changes in rice under drought [123]. Cell growth is impaired by decreases in turgor pressure under stress [124]. Drought impacts both expansion growth and elongation [125] and inhibits cell enlargement more than cell division [126]. Additionally, it inhibits rice seedling germination [127] and decreases the number of tillers $[128,129]$ and plant height $[130]$. A reduction in biomass production is a common adverse effect of drought stress [131]. Several studies have revealed a reduction in the dry and fresh weights of roots [10] and shoots [128] under drought. Reductions in fresh root and shoot weights and lengths ultimately reduce the biochemical processes and photosynthetic rate in rice [132].

4.1. The Effect of Drought Stress on Yield. The grain yield of rice severely decreases under drought stress [133]. Drought stress at the booting [134] and flowering stages disrupts floret initiation, leading to slow grain filling and spikelet sterility and resulting in reduced grain weight and poor paddy yield [135]. The most common characteristics of rice under drought stress include decreases grain weight and size [128], the 1000grain weight, and seed-setting rate [10] and increases in spikelet sterility [136]. Water deficits restrict the grain filling period, resulting in in reduced grain yields [137]. Drought stress disrupts leaf gas exchange, limits the sizes of source and sink tissues, and impairs assimilate translocation and phloem loading [138]. Drops in yield may be due to reductions in $\mathrm{CO} 2$ assimilation rates induced by drought or decreases in photosynthetic pigments, stomatal conductance, stem extension, water use efficiency, the activities of starch and sucrose biosynthetic enzymes, and assimilate partitioning, resulting in reduced growth and productivity of the plant [139]. Drought duration and crop growth stage are two determinants of grain yield loss [140], as is the harshness of the drought stress [136]. Genetic, physiological, morphological, and ecological events and their multifaceted interactions are involved in cell division, enlargement, and differentiation and affect plant growth. Drought stress strongly affects the quantity and quality of plant growth through three main steps (Figure 1).

Cell growth is limited significantly due to reductions in turgor pressure under drought stress [124]. Cell elongation in higher plants under severe drought stress may be limited by disrupted water flow between the xylem and the surrounding elongating cells [141]. Reductions in mitosis, cell elongation, and cell expansion cause decreases in plant leaf area, height, and crop growth under water deficit [141, 142]. 


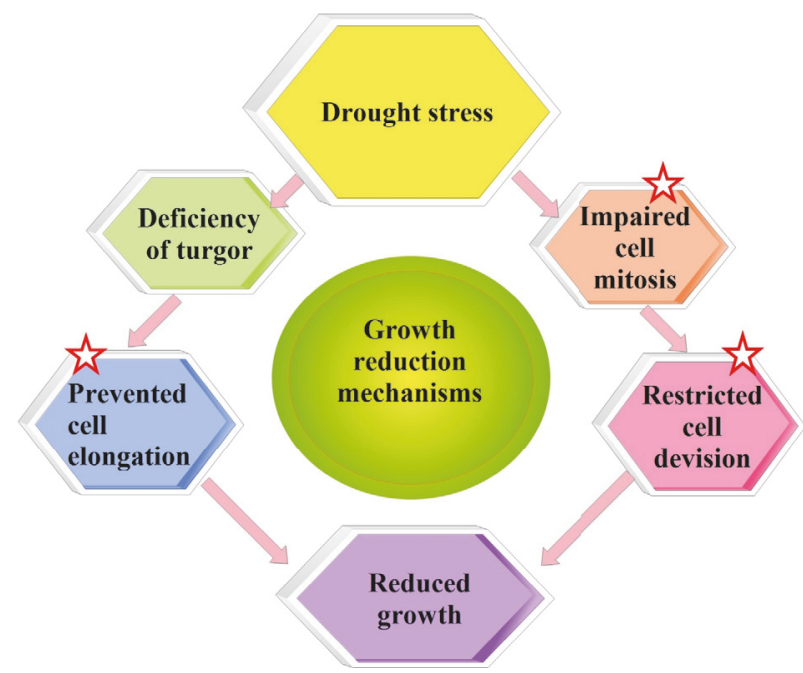

Figure 1: Annotation mechanisms of growth decline under drought stress condition. Under water deficit condition, cell elongation is hindered in higher plants by lessened turgor pressure. Decreased water uptake leads to reduce in tissue water contents. Consequently, turgor is missing. Similarly, water deficit condition also decreases the metabolites and photo assimilation required for the cell division. As a result, spoiled mitosis, cell elongation, and expansion lead to decreased growth.

\subsection{Global Strategies for Studying the Genetics of Drought} Tolerance in Low-Yielding Areas. Molecular and physiological breeding approaches to improve drought tolerance in rice have not been very successful to date and suggest the need for a careful rethinking of our strategies. Some recently developed plant genomics platforms and methods may help overcome earlier limitations; the other techniques may have led us down incorrect paths. There are three main approaches to improve drought tolerance in rice and other crops: (i) experience-based selection for rice varieties with high yields under water deficit: this method has been widely used, and the excellent morphology of new cultivars is evidence of the success of this method. However, many studies have shown that the grain yield of these cultivars may not be sufficient to meet demand [143]; (ii) expression of physiological ideotypes for rice under drought to improve yield, then identifying sources of variation for these traits to introduce into selected varieties: in other words, genomics, breeding, and physiology approaches are integrated to improve drought tolerance in rice [144]. For this purpose, screening elite tolerance cultivars with high water use efficiency (WUE) using carbon isotopes is strongly suggested; and (iii) use of marker-assisted selection to screen for QTLs, including desirable alleles for drought tolerance.

A comprehensive research programme or a multidisciplinary method of integrating the physiology of drought tolerance traits with genomics and genetic tools, including quantitative trait loci, suppression subtractive hybridization, microarrays, and different transgenic crops is needed to enhance drought tolerance in rice. A complete pathway towards improving drought tolerance in rice by discovering candidate genes is illustrated (Figure 2) and briefly described in this paper and includes (i) selecting a specific environment, (ii) creating controlled populations by selecting germplasm adapted to the target environment, (iii) describing

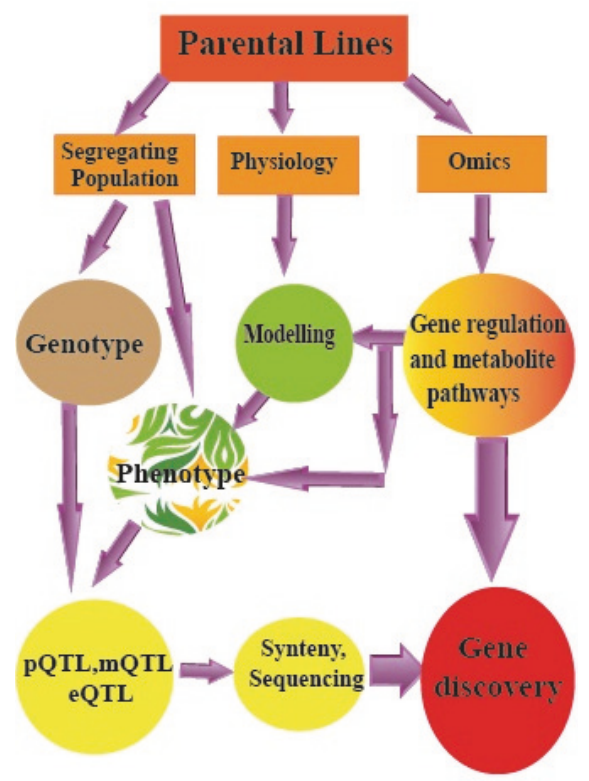

FIGURE 2: The schematic pathway from selection of parental lines to gene identified. The diagram presents the importance of population development, physiological analysis, phenotyping, and different 'omics technologies towards discovering a novel responsive gene. Investigation of the drought regime type is the main and first step. Selection suitable germplasm based on target environment, which possibly leads to release majority of loci related to tolerance, is the next issue. The selected lines then will be used to improve segregating populations required for genetic analysis. Selection recombinant lines based on parental omics and physiological traits using different mathematical models offer functional data to choice candidate genes and work on QTLs.

the morphological, molecular, and physiological mechanisms involved in the tolerance of the parents, and (iv) integrating 
this information into models used for QTL analysis and positional cloning (Figure 2).

4.3. Focus on a Specific Environment. Drought tolerance experiments should be carried out under a realistic environment and field conditions. Most reports by molecular biologists consider the effects of genes responsible for drought tolerance under unrealistic conditions; they seldom prove their value for breeders or their expected phenotypes under field conditions [145].

On the other hand, different plants have developed their morphology and physiological mechanisms exclusively to tolerate different types of drought stresses. There are different root systems developed by different plants under drought conditions to improve the timing of water absorption from the soil. A deep, compact root system increases yield via stored soil moisture by presenting a uniform branching pattern that enhances water use efficiency by reducing the use of water early in the season and increasing access to water during grain filling [146]. Plants from the Mediterranean, which experiences seasonal rainfall along with terminal drought, have large and narrow root systems to extract water from the top layers of soil early in the season [146]. A QTL under drought may have different additive positive, null, or negative effects because of interactions between genotype and the environment [147]. Identified QTLs responsible for drought stress may not be stable in different environmental conditions. They can be classified as constitutive or adaptive based on the stability of their effects across different environmental conditions. Constitutive QTLs are regularly identified across different environments, whereas adaptive QTLs are identified only under particular environmental conditions, and their expression is affected by changing in the environmental factor [148]. Therefore, the occurrence and magnitude of adaptive QTLs differ between experiments, but stable QTLs easily help to understand the same trait under a range of environmental conditions.

Adaptive QTLs are sensitive to any changes in environmental conditions; the QTL gene is regulated by an environmental signal. Alternatively, different responses to environmental changes may be due to the genotype; for example, larger root systems are less affected by nutrient deficit and water shortage than are small root systems. Hence, genes involved in the development of root systems may support QTLs involved in stomatal conductance, abscisic acid content, and biomass accumulation. Moreover, QTLs responsible for flowering time usually affect plant yield under water and nutrient shortages because the period of the plant life cycle influences the intensity and timing of the stresses [149]. Accordingly, the unpredictable effects revealed by most QTLs on yield in diverse environments are not surprising. Thus, describing a target drought scenario is the most important issue for a research programme on drought tolerance.

\section{Drought Stress Omics}

A dataset including alterations in gene expression, protein profiling, and metabolites found in plants under drought conditions should be produced using genomics tools. Monocotyledonous and dicotyledonous plants use the same transcription factors under abiotic stress [150]. The molecular mechanisms in drought-tolerant plants include (i) a signal transduction cascade followed by transcriptional activation and regulation; (ii) protein protection with help of many proteins, such as late embryogenesis abundant-like dehydrins or chaperones such as heat shock proteins; (iii) the accumulation of osmolytes, including mannitol, betaine, proline, trehalose, myo-inositol, and glycine; (iv) the induction of chemical antioxidants, such as glutathione and ascorbic acid; and (v) the reduction of reactive oxygen species (ROS) toxicity by superoxide dismutase and glutathione S-transferase. These different mechanisms may involve several homologous genes that can be identified via transcriptomic experiments on rice lines grown under normal or water stress conditions. Several regulatory mechanisms for drought tolerance are found in many species, but the molecular response to water stress has been experimentally shown [151] to be less consistent because of differences in developmental stage, stress dynamics, and tissue analysed.

5.1. The Zinc Finger Protein Family in Rice. In rice, different biological processes are controlled by different transcription factors encoded by WRKY genes. Zinc finger proteins, particularly those that regulate stress responses, are widely distributed in plants. The WRKY genes are broadly distributed among plants and are present in monocotyledons and dicotyledons. Many WRKY genes play positive or negative regulatory roles in plant responses to different biotic and abiotic stresses [152]. As one of the largest transcription factor families, WRKY transcription factors play key roles in regulating many plant processes, including the response to drought stress [153]. The WRKY proteins contain one or two WRKY domains, which include a WRKY motif and a Zn finger motif. The structure of the DNA-binding domain is the basis for the differentiation of the WRKY family members. The main sequences of WRKY motifs are formed based on variations of the WRKYGQK motif, such as WRKYGKK, WRKYGEK, WKKYGQK, WRKYGRK, WSKYEQK, and WKRYGQK [154]. Two types of $\mathrm{C} 2 \mathrm{H} 2$ motifs, (C-X4-5-C-X22-23-H-X1-H) and (C-X5-7-C-X23-H-X1-C), are the $\mathrm{Zn}$ fingers found in WRKY proteins $[155,156]$. The WRKY proteins are divided into three different groups. Group I contains two WRKY domains and is divided into subgroup Ia, which contains $\mathrm{C}_{2} \mathrm{H}_{2} \mathrm{Zn}$ ingers, and subgroup Ib, which contains $\mathrm{C}_{2} \mathrm{HC} \mathrm{Zn}$ fingers; group II contains one WRKY domain that is based on short conserved motifs, and this group is further subdivided into five subgroups, a-e, according to their phylogenetic relationship [156]. Group III members have a WRKY domain with a different $\mathrm{Zn}$ finger, $\mathrm{C}_{2} \mathrm{HC}$ [155].

Rice contains more WRKY protein family members than does Arabidopsis. The sequencing and curation of two highly productive rice genomes, japonica cv. Nipponbare [157] and wild type $O$. nivara, provide an opportunity to evaluate a large family of transcription factors. Japonica cv. Nipponbare presents a wide range of tolerance against environmental stresses [158]. In addition, O. nivara displays rich genetic 


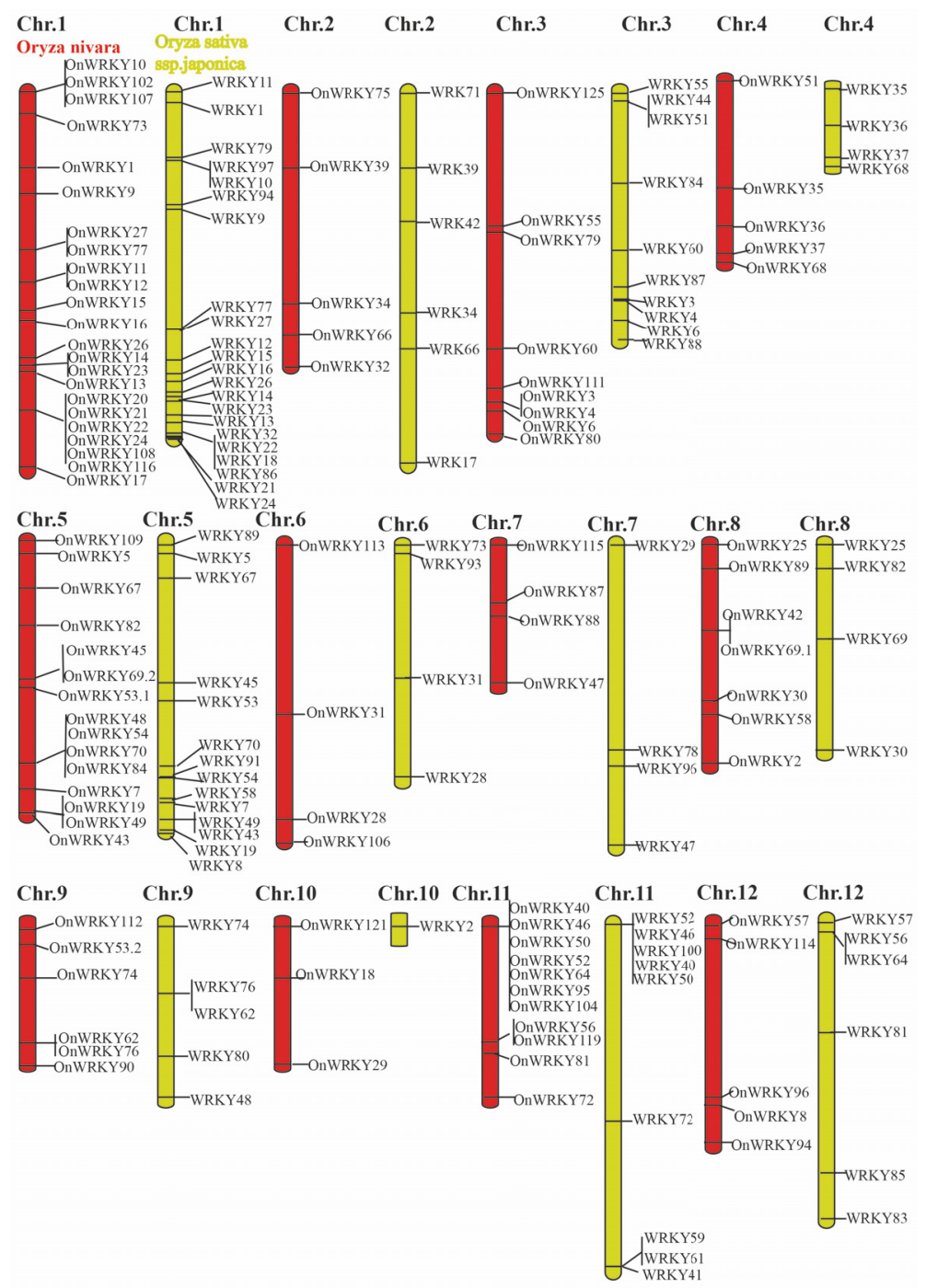

FIGURE 3: Distribution of the WRKY gene family on the Oryza sativa ssp. japonica chromosomes (right) and wild type O. nivara chromosomes chromosome (left). The columns symbolize chromosomes with the name of genes shown on the right.

diversity [159] and elite drought tolerance [158]; hence, any differences in the WRKY family that are associated with the regulation of responses toward abiotic stresses, particularly drought stress, would be of interest. The HMMER program [160] was used to identify WRKY genes in japonica cv. Nipponbare and indica cv. Nivara and to construct a hidden Markov model (HMM) using Oryza sativa WKRY proteins $[155,161]$. Non-WRKY proteins were removed by screening the results manually for false positives at an e-value $>10$. A batch BLASTp [162] was performed to identify orthologues by comparing WKRY sequences in $O$. Nipponbare and $O$. Nivara. Mapping these transcription factors to individual chromosomes eased the removal of redundancies and facilitated the identification of 89 WRKY genes in japonica and 97 in wild type O. nivara (Figure 3). Two copies of WRKY46 were identified on chromosomes 11 and 12. OnWKRY39 and OnWRKY66 seem to be duplicated in O. Nivara and have tandem repeats on chromosome 2. OnWKRY25 appears to be duplicated on chromosome 8 of O. Nivara. Similarly, duplications of OnWKRY40, OnWRKY46, OnWRKY50, and OnWRKY52 could be found in O. Nivara on chromosome 11. Lastly, OnWKRY57 appears to be duplicated in O. Nivara on chromosome 12. The inequalities in the WRKY genes and the different loci of some WRKY genes between Japonica and $O$. Nivara may contribute to the differences in their ability to cope with different stresses. On the other hand, it may be due to incorrectly identified exons or errors in the detection of intron-exon boundaries or scaffold assembly. Hence, the complete annotation of the WKRY gene family requires additional substantial cDNA cloning and sequencing.

\section{The Role of Photosynthesis and Photosynthetic Pigments in the Drought Response}

Among various metabolic processes, photosynthesis is a vital complex process during drought stress. The most important 


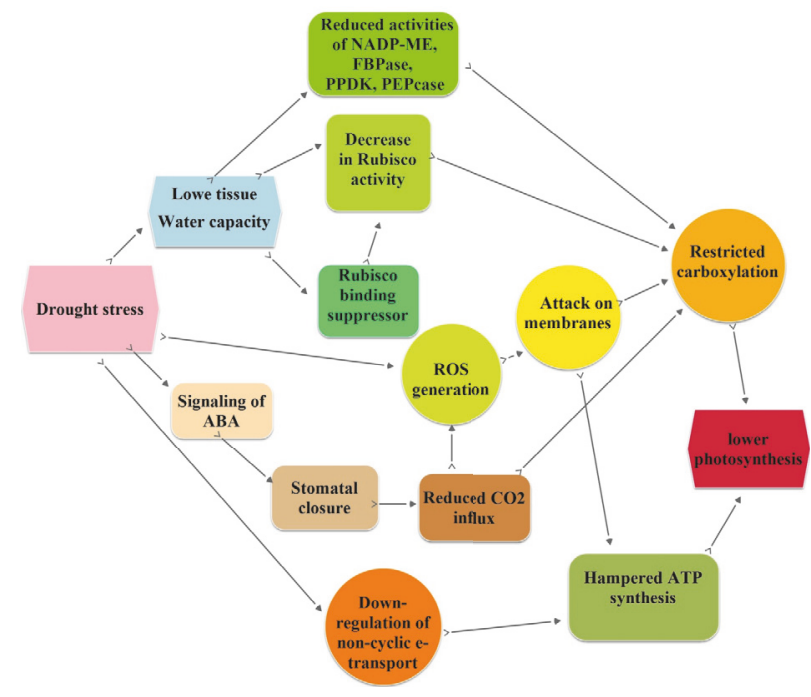

Figure 4: Possible mechanisms of photosynthesis under drought stress.

factors that limit photosynthesis are the $\mathrm{CO}_{2}$ diffusional restriction because of decreased reductions in photosynthesis, early stomatal closure, and the decreased efficiency of PSII photochemical formation and the biochemical components related to triose phosphate formation. Alterations in any of these components change the overall photosynthetic rate. Mesophyll conductance $(\mathrm{gm})$ and stomatal conductance $(g \mathrm{~s})$ to $\mathrm{CO}_{2}$ often decrease under drought stress [163]. Hence, maintenance of the $g \mathrm{~m}$ values under drought stress reflects the tolerance of rice to water deficits [164]. The PSII activity is crucial for providing ATP and power. If PSII activity increases, an excessive decrease in the electron transport chain in the photosynthetic apparatus may occur, thereby stimulating the production of ROS. Accordingly, a balance between demand for photoassimilates and photochemical activity is necessary. Drought stress significantly impairs the activity of PSII in rice flag leaves [165]. This phenomenon occurs because drought induces the degradation of the D1 polypeptide, causing the inactivation of the PSII reaction centre. Drought stress restricts photosynthesis due to a tendency for the activity of Rubisco, a Calvin cycle enzyme, to decrease [166]. Nevertheless, the amount of Rubisco activase promotes ATP-dependent conformational changes, rescues Rubisco sites from dead-end inhibition, and can increase as a protective mechanism under drought stress. Currently, enzymes involved in $\mathrm{C}_{4}$ crop photosynthesis have been introduced into rice to alter photosynthesis and plant productivity in response to stress. Transgenic rice plants overexpressing $\mathrm{C}_{4}$ photosynthesis enzymes, such as phosphoenolpyruvate carboxylase and pyruvate orthophosphate dikinase, are highly drought tolerant [167] (Figure 4).

Drought leads to various alterations in metabolic functions, one of the most important of which is the reduction or loss of photosynthetic pigment synthesis. This causes reduced light harvesting and reducing power, which act as an energy source for the dark reactions of photosynthesis.
Changes in the amounts of photosynthetic pigments are closely associated with biomass and yield [126]. The photosynthetic pigment chlorophyll absorbs light energy and transfers the energy to the photosystem reaction centre. Among various chlorophylls, chlorophylls a and b, which are typically found in higher plants, are susceptible to soil drying. Additionally, other pigments, carotenoids, have various functions in light harvesting, chloroplast photosystem structure, and photoprotection, and can partially promote crop resistance to drought. Decreases in chlorophyll content and the maximum quantum yield of PSII $(F \mathrm{v} / F \mathrm{Fm})$ have been observed in several studies on rice under drought stress $[133,168]$. Decreases in $F \mathrm{v} / F \mathrm{~F}$ and chlorophyll content have been observed less frequently in autotetraploid lines than in their corresponding diploid lines under drought stress, suggesting that autotetraploid rice is more tolerant of drought stress [169]. The reduction in chlorophyll content may occur because stress impairs pigment degradation or pigment biosynthetic networks and increases lipid peroxidation and the loss of the chloroplast membrane.

\section{The Biochemical Response of Rice under Drought}

Reduced osmotic potential in the cytosol is as a result of the accumulation of inorganic and organic solutes, which leads to the maintenance of turgor pressure under drought stress [170]. This biochemical procedure is a type of osmotic adaptation that strongly depends on the water stress level. Osmotic adaptation occurs via the accumulation of glycine betaine, sucrose, proline, and other solutes in the cytoplasm, promoting water uptake by drying the soil. Proline, an amino acid, is the most widely investigated due to its considerable stress-reducing or function under adverse conditions. Water deficit also induces soluble sugar accumulation [132, 133, 171]. 
7.1. The Role of Proline under Drought. As mentioned above, proline acts as an osmolyte in plants under various adverse conditions [172]. The initial report regarding the role of proline role was made in 1954, when Kemble and MacPherson studied free proline accumulation in rye grasses exposed to stress [173]. The differences in proline accumulation under normal and stress conditions have been reported in rice [128, $133,136,174]$. Additionally, proline exhibits three main roles under stress, i.e., as a signalling molecule, an antioxidative defence molecule, and a metal chelator [175]. Under drought stress, the accumulation of this amino acid might repair damage by increasing the rate of antioxidant activity [176]. Thus, the proline content can be used as a marker to screen for drought screening tolerance in rice.

7.2. The Role of Antioxidants under Drought. An imbalance between the quenching and generation of ROS is the most common phenomenon under drought stress [177]. The ROS include hydroxyl free radicals, singlet oxygen, hydrogen peroxide, and the superoxide radical, and they denature proteins, cause lipid peroxidation, mutate DNA, disrupt cellular homeostasis, and cause cellular oxidative damage. A complex antioxidant system containing enzymatic antioxidants and nonenzymatic molecules protects plants against the adverse effect of ROS. Glutathione (GSH) and ascorbate (AsA) serve as nonenzymatic antioxidants within the cell. Enzymatic antioxidants include catalase (CAT), glutathione reductase (GR), ascorbate peroxidase (APX), superoxide dismutase (SOD), guaiacol peroxidase (GPX), ascorbate-glutathione cycle enzyme, monodehydroascorbate reductase (MDHAR), and dehydroascorbate reductase (DHAR) [178]. These antioxidants are vital ROS-scavenging components in crops, and their expression increases drought tolerance in rice [179]. Increasing levels of drought stress in rice lead to increases in the activity of APX, GSH, AsA [180], GR, MDHAR, SOD, DHAR [181], CAT, and phenylalanine ammonia lyase [171]. The trend for these antioxidant defence enzymes to increase their activity demonstrates their protective activity to counteract the oxidative injury induced by drought stress in rice. The activities of CAT, POD, and SOD can effectively decrease ROS, which ultimately diminishes the negative impact of drought on rice $[169,174]$.

7.3. The Role of Polyamines under Drought. Polyamines (PAs) are small positively charged molecules [182] that are a part of the drought tolerance response in plants [183]. The PAs in plants include spermine (Spm), spermidine (Spd), and putrescine (Put). Polyamines can interact with different signalling networks. Additionally, they regulate ionic homeostasis and osmotic potential and stabilize membranes. The increased PA content of plants exposed to drought is directly correlated with decreased water loss, increased photosynthetic capacity, and improved osmotic detoxification and adjustment. However, the full network of action is poorly understood. The roles of PAs encompass regulating gene expression via maintaining ion balance, facilitating the DNA binding of transcription factors, scavenging radicals, stabilizing membranes, and preventing senescence via the conformational transition of DNA and protein phosphorylation [184]. A recent study has demonstrated that rice can promote PA biosynthesis, especially the free forms of Spm and Spd, and conjugate them into insoluble forms in leaves previously exposed to drought stress [185]. Exogenous PAs can reduce drought stress. Their application improves WUE, free proline production, net photosynthesis, leaf water status, soluble phenolics, and anthocyanins and decreases oxidative damage to cellular membranes [138].

\section{Conclusions}

Traditional breeding approaches to select for improved genotypes depend on phenotypic traits, but they are only partially successful because direct selection is hampered by low heritability, genotype-environment interactions, genetic interactions such as epistasis, and polygenic effects. Our knowledge of the drought tolerance mechanism has increased via research programmes focused on particular physiological, molecular, and genetic aspects of the drought response. None of these approaches have successfully suppressed the drought susceptibility of rice. However, the integrative plan to link physiology, quantitative genetics, and omics, as recommended above, has been followed by a few research programmes. Accurate phenotyping is critical to screen for superior core mapping populations/collections to identify the most relevant QTLs and isolate candidate gene(s) used in plant breeding. Compared with phenotypic selection, GS selection can reduce the selection time for most traits and has emerged as an important method to predict genotype performance. The WRKY genes play important roles in plant development by responding to different biotic and abiotic stresses, and these transcription factors have undergone numerous duplications and deletions in the recent evolution of Oryza sativa. Annotation of the WRKY family in rice will help determine whether these events are associated with the variation among recent rice cultivars and subspecies or are neutral occurrences in a highly redundant transcription factor family. Combinations of different phenotyping methods and modelling present great potential to swiftly assess the value of definite traits on plant performance. Using models to understand relationships between genotype and phenotype in plants offers an effective platform to create new interactions between genomics/genetics and plant physiology [186]. To overcome the challenge of increasing crop production, systems biology and functional genomics at the crop level should be integrated, and crop physiology will play an important role in achieving this goal. The abundant genomics and genetic analyses of rice offer the opportunity to generate large populations and greatly improved field phenotyping abilities. Nevertheless, genetic studies have not permitted the real dissection of plant responses to drought stress and have not focused on definite drought conditions or regimes. New advances in marker development, sequencing, and genomic analysis have provided the opportunity to reconsider the method of creating populations suitable for analysis and to challenge the precise players in drought tolerance. The rate-limiting and expensive phenotyping step has become a great challenge in analysing drought tolerance and other 
crop traits. Therefore, the development of rapid and cheap measures to characterize drought response components will effectively improve genetic resolution.

\section{Conflicts of Interest}

The authors declare that they have no conflicts of interest.

\section{Acknowledgments}

The senior author (Mahbod Sahebi) would like to express sincere gratitude to the Universiti Putra Malaysia for providing the Higher Institution Centers of Excellence (HICoE) research Grant (HICoE-ITAFoS/2017/FC6, vote no. 6369105) for the financial support and research facilities.

\section{References}

[1] J. A. Foley, N. Ramankutty, K. A. Brauman et al., "Solutions for a cultivated planet," Nature, vol. 478, no. 7369, pp. 337-342, 2011.

[2] P. Alpert, "The limits and frontiers of desiccation-tolerant life," Integrative and Comparative Biology, vol. 45, no. 5, pp. 685-695, 2005.

[3] P. Berjak, M. Walker, M. P. Watt, and D. J. Mycock, "Experimental parameters underlying failure or success in plant germplasm cryopreservation: A case study on zygotic axes of Quercus robur L.," Cryoletters, vol. 20, no. 4, pp. 251-262, 1999.

[4] Ntuli, T.M. (2012) Drought and Desiccation-Tolerance and Sensitivity in Plants. INTECH Open Access Publisher.

[5] F. A. Hoekstra, E. A. Golovina, and J. Buitink, "Mechanism of plant desiccation tolerance," Trends in Plant Science, vol. 6, no. 9, pp. 431-438, 2001.

[6] C. Tanford, "The hydrophobic effect and the organization of living matter," Science, vol. 200, no. 4345, pp. 1012-1018, 1978.

[7] N. Honsdorf, T. J. March, B. Berger, M. Tester, and K. Pillen, "High-throughput phenotyping to detect drought tolerance QTL in wild barley introgression lines," PLoS ONE, vol. 9, no. 5, Article ID e97047, 2014.

[8] S. Ashkani, M. Y. Rafii, M. Shabanimofrad et al., "Molecular breeding strategy and challenges towards improvement of blast disease resistance in rice crop," Frontiers in Plant Science, vol. 6, p. 886, 2015.

[9] G. S. Khush, "What it will take to feed 5.0 billion rice consumers in 2030," Plant Molecular Biology, vol. 59, no. 1, pp. 1-6, 2005.

[10] K. Ji, Y. Wang, W. Sun et al., "Drought-responsive mechanisms in rice genotypes with contrasting drought tolerance during reproductive stage," Journal of Plant Physiology, vol. 169, no. 4, pp. 336-344, 2012.

[11] R. Serraj, K. L. McNally, I. Slamet-Loedin et al., "Drought resistance improvement in rice: An integrated genetic and resource management strategy," Plant Production Science, vol. 14, no. 1, pp. 1-14, 2011.

[12] B. P. M. Swamy and A. Kumar, "Genomics-based precision breeding approaches to improve drought tolerance in rice," Biotechnology Advances, vol. 31, no. 8, pp. 1308-1318, 2013.

[13] M. Iqbal, M. A. Khan, M. Naeem, U. Aziz, J. Afzal, and M. Latif, "Inducing drought tolerance in upland cotton (Gossypium hirsutum L.), accomplishments and future prospects," World Applied Sciences Journal, vol. 21, no. 7, pp. 1062-1069, 2013.
[14] J. M. Hansen, Y. M. Go, and D. P. Jones, "Nuclear and mitochondrial compartmentation of oxidative stress and redox signaling," Annual Review of Pharmacology and Toxicology, vol. 46, pp. 215-234, 2006.

[15] V. Pandey and A. Shukla, "Acclimation and Tolerance Strategies of Rice under Drought Stress," Rice Science, vol. 22, no. 4, pp. 147-161, 2015.

[16] D. Fleury, S. Jefferies, H. Kuchel, and P. Langridge, "Genetic and genomic tools to improve drought tolerance in wheat," Journal of Experimental Botany, vol. 61, no. 12, pp. 3211-3222, 2010.

[17] T. R. Sinclair, "Challenges in breeding for yield increase for drought," Trends in Plant Science, vol. 16, no. 6, pp. 289-293, 2011.

[18] R. Tuberosa, "Phenotyping for drought tolerance of crops in the genomics era," Frontiers in Physiology, vol. 3, 2012.

[19] R. K. Varshney, K. C. Bansal, P. K. Aggarwal, S. K. Datta, and P. Q. Craufurd, "Agricultural biotechnology for crop improvement in a variable climate: Hope or hype?" Trends in Plant Science, vol. 16, no. 7, pp. 363-371, 2011.

[20] S. Chamarthi, A. Kumar, T. Vuong et al., Trait mapping and molecular breeding, in Biology and breeding of food legumes, $\mathrm{P}$. A. and K. J., Eds., CABI International, Oxfordshire, U.K., 2011.

[21] J. M. Lilley, M. M. Ludlow, S. R. McCough, and J. C. O’Toole, "Locating QTL for osmotic adjustment and dehydration tolerance in rice," Journal of Experimental Botany, vol. 47, no. 302, pp. 1427-1436, 1996.

[22] A. H. Price, J. Townend, M. P. Jones, A. Audebert, and B. Courtois, "Mapping QTLs associated with drought avoidance in upland rice grown in the Philippines and West Africa," Plant Molecular Biology, vol. 48, no. 5-6, pp. 683-695, 2002.

[23] P. Mu, Z. Li, C. Li et al., "QTL mapping of the root traits and their correlation analysis with drought resistance using $\mathrm{DH}$ lines from paddy and upland rice cross," Chinese Science Bulletin, vol. 48, no. 24, pp. 2718-2724, 2003.

[24] B. Courtois, L. Shen, W. Petalcorin, S. Carandang, R. Mauleon, and Z. Li, "Locating QTLs controlling constitutive root traits in the rice population IAC 165 x Co39," Euphytica, vol. 134, no. 3, pp. 335-345, 2003.

[25] R. C. Babu, B. D. Nguyen, V. Chamarerk et al., "Genetic analysis of drought resistance in rice by molecular markers: Association between secondary traits and field performance," Crop Science, vol. 43, no. 4, pp. 1457-1469, 2003.

[26] J. C. Lanceras, G. Pantuwan, B. Jongdee, and T. Toojinda, "Quantitative trait loci associated with drought tolerance at reproductive stage in rice," Plant Physiology, vol. 135, no. 1, pp. 384-399, 2004.

[27] L. Li-Feng, Z. Hong-Liang, M. Ping, Q. Yan-Ying, and L. ZiChao, "Construction and evaluation of near-isogenic lines for major QTLs of basal root thickness and 1000-grain-weight in lowland and upland rice," Chinese Journal of Agricultural Biotechnology, vol. 4, no. 03, 2007.

[28] S. HU, H. YANG, G. ZOU et al., "Relationship Between Coleoptile Length and Drought Resistance and Their QTL Mapping in Rice," Rice Science, vol. 14, no. 1, pp. 13-20, 2007.

[29] Y. Kato, S. Hirotsu, K. Nemoto, and J. Yamagishi, "Identification of QTLs controlling rice drought tolerance at seedling stage in hydroponic culture," Euphytica, vol. 160, no. 3, pp. 423-430, 2008.

[30] J. Bernier, A. Kumar, V. Ramaiah, D. Spaner, and G. Atlin, "A large-effect QTL for grain yield under reproductive-stage 
drought stress in upland rice," Crop Science, vol. 47, no. 2, pp. 507-518, 2007.

[31] J. Bernier, R. Serraj, A. Kumar et al., "The large-effect droughtresistance QTL qtl12.1 increases water uptake in upland rice," Field Crops Research, vol. 110, no. 2, pp. 139-146, 2009.

[32] R. Venuprasad, C. O. Dalid, M. Del Valle et al., "Identification and characterization of large-effect quantitative trait loci for grain yield under lowland drought stress in rice using bulksegregant analysis," Theoretical and Applied Genetics, vol. 120, no. 1, pp. 177-190, 2009.

[33] K. K. Mishra, P. Vikram, R. B. Yadaw et al., "QDTY12.1: A locus with a consistent effect on grain yield under drought in rice," BMC Genetics, vol. 14, article no. 12, 2013.

[34] R. B. Yadaw, S. Dixit, A. Raman et al., "A QTL for high grain yield under lowland drought in the background of popular rice variety Sabitri from Nepal," Field Crops Research, vol. 144, pp. 281-287, 2013.

[35] X. Wang, Y. Pang, J. Zhang et al., "Genetic background effects on QTL and QTL $\times$ environment interaction for yield and its component traits as revealed by reciprocal introgression lines in rice," Crop Journal, vol. 2, no. 6, pp. 345-357, 2014.

[36] A. D. Palanog, B. P. M. Swamy, N. A. A. Shamsudin et al., "Grain yield QTLs with consistent-effect under reproductivestage drought stress in rice," Field Crops Research, vol. 161, pp. 46-54, 2014.

[37] S. Saikumar, P. Kalmeshwer Gouda, A. Saiharini et al., "Major QTL for enhancing rice grain yield under lowland reproductive drought stress identified using an $O$. sativa/O. glaberrima introgression line," Field Crops Research, vol. 163, pp. 119-131, 2014.

[38] S. J. Prince, R. Beena, S. M. Gomez, S. Senthivel, and R. C. Babu, "Mapping Consistent Rice (Oryza sativa L.) Yield QTLs under Drought Stress in Target Rainfed Environments," Rice, vol. 8, no. 1, 2015.

[39] R. Singh, Y. Singh, S. Xalaxo et al., "From QTL to varietyharnessing the benefits of QTLs for drought, flood and salt tolerance in mega rice varieties of India through a multiinstitutional network," Journal of Plant Sciences, vol. 242, pp. 278-287, 2015.

[40] M. Seo, A. J. M. Peeters, H. Koiwai et al., "The Arabidopsis aldehyde oxidase 3 (AAO3) gene product catalyzes the final step in abscisic acid biosynthesis in leaves," Proceedings of the National Acadamy of Sciences of the United States of America, vol. 97, no. 23, pp. 12908-12913, 2000.

[41] T. Kuromori, E. Sugimoto, and K. Shinozaki, "Arabidopsis mutants of AtABCG22, an ABC transporter gene, increase water transpiration and drought susceptibility," The Plant Journal, vol. 67, no. 5, pp. 885-894, 2011.

[42] J.-Y. Kang, H.-I. Choi, M.-Y. Im, and Y. K. Soo, "Arabidopsis basic leucine zipper proteins that mediate stress-responsive abscisic acid signaling," The Plant Cell, vol. 14, no. 2, pp. 343357, 2002.

[43] J. Kang, J.-U. Hwang, M. Lee et al., "PDR-type ABC transporter mediates cellular uptake of the phytohormone abscisic acid," Proceedings of the National Acadamy of Sciences of the United States of America, vol. 107, no. 5, pp. 2355-2360, 2010.

[44] T. Kuromori, T. Miyaji, H. Yabuuchi et al., "ABC transporter AtABCG25 is involved in abscisic acid transport and responses," Proceedings of the National Acadamy of Sciences of the United States of America, vol. 107, no. 5, pp. 2361-2366, 2010.
[45] V. Hugouvieux, J. M. Kwak, and J. I. Schroeder, "An mRNA cap binding protein, $\mathrm{ABH}$, modulates early abscisic acid signal transduction in Arabidopsis," Cell, vol. 106, no. 4, pp. 477-487, 2001.

[46] Z. Chen, H. Zhang, D. Jablonowski et al., "Mutations in $\mathrm{ABO} 1 / \mathrm{ELO} 2$, a subunit of holo-elongator, increase abscisic acid sensitivity and drought tolerance in Arabidopsis thaliana," Molecular and Cellular Biology, vol. 26, no. 18, pp. 6902-6912, 2006.

[47] S.-J. Lee, D.-I. Cho, J.-Y. Kang, and S. Y. Kim, "An ARIAinteracting AP2 domain protein is a novel component of ABA signaling," Molecules and Cells, vol. 27, no. 4, pp. 409-416, 2009.

[48] W. Li, X. Cui, Z. Meng et al., "Transcriptional regulation of arabidopsis MIR168a and ARGONAUTE1 homeostasis in abscisic acid and abiotic stress responses," Plant Physiology, vol. 158, no. 3, pp. 1279-1292, 2012.

[49] L.-S. P. Tran, T. Urao, F. Qin et al., "Functional analysis of AHK1/ATHK1 and cytokinin receptor histidine kinases in response to abscisic acid, drought, and salt stress in Arabidopsis," Proceedings of the National Acadamy of Sciences of the United States of America, vol. 104, no. 51, pp. 20623-20628, 2007.

[50] M. Y. Ryu, S. K. Cho, and W. T. Kim, “The arabidopsis C3H2C3type RING E3 Ubiquitin ligase AtAIRP1 is a positive regulator of an abscisic acid-dependent response to drought stress," Plant Physiology, vol. 154, no. 4, pp. 1983-1997, 2010.

[51] Q. Liu, M. Kasuga, Y. Sakuma et al., “Two transcription factors, DREB1 and DREB2, with an EREBP/AP2 DNA binding domain separate two cellular signal transduction pathways in droughtand low-temperature-responsive gene expression, respectively, in Arabidopsis," The Plant Cell, vol. 10, no. 8, pp. 1391-1406, 1998.

[52] C. Lu and N. Fedoroff, "A mutation in the Arabidopsis HYL1 gene encoding a dsRNA binding protein affects responses to abscisic acid, auxin, and cytokinin," The Plant Cell, vol. 12, no. 12, pp. 2351-2365, 2000.

[53] L. Xiong, M. Ishitani, H. Lee, and J.-K. Zhu, “The Arabidopsis LOS5/ABA3 locus encodes a molybdenum cofactor sulfurase and modulates cold stress- and osmotic stress-responsive gene expression," The Plant Cell, vol. 13, no. 9, pp. 2063-2083, 2001.

[54] R. A. Gaxiola, J. Li, S. Undurraga et al., "Drought- and salttolerant plants result from overexpression of the AVP1 H+pump," Proceedings of the National Acadamy of Sciences of the United States of America, vol. 98, no. 20, pp. 11444-11449, 2001.

[55] S. Iuchi, M. Kobayashi, T. Taji et al., "Regulation of drought tolerance by gene manipulation of 9-cis-epoxycarotenoid dioxygenase, a key enzyme in abscisic acid biosynthesis in Arabidopsis," The Plant Journal, vol. 27, no. 4, pp. 325-333, 2001.

[56] T. Taji, C. Ohsumi, S. Iuchi et al., "Important roles of droughtand cold-inducible genes for galactinol synthase in stress tolerance in Arabidopsis thaliana," The Plant Journal, vol. 29, no. 4, pp. 417-426, 2002.

[57] D. Konopka-Postupolska, G. Clark, G. Goch et al., "The role of annexin 1 in drought stress in Arabidopsis," Plant Physiology, vol. 150, no. 3, pp. 1394-1410, 2009.

[58] J. B. Rossel, P. B. Walter, L. Hendrickson et al., "A mutation affecting ASCORBATE PEROXIDASE 2 gene expression reveals a link between responses to high light and drought tolerance," Plant, Cell \& Environment, vol. 29, no. 2, pp. 269281, 2006.

[59] T. Furihata, K. Maruyama, Y. Fujita et al., "Abscisic aciddependent multisite phosphorylation regulates the activity of a transcription activator AREB1," Proceedings of the National 
Acadamy of Sciences of the United States of America, vol. 103, no. 6, pp. 1988-1993, 2006.

[60] S. J. Kim and W. T. Kim, "Suppression of Arabidopsis RING E3 ubiquitin ligase AtATL78 increases tolerance to cold stress and decreases tolerance to drought stress," FEBS Letters, vol. 587, no. 16, pp. 2584-2590, 2013.

[61] K. H. Lee, H. L. Piao, H.-Y. Kim et al., "Activation of Glucosidase via Stress-Induced Polymerization Rapidly Increases Active Pools of Abscisic Acid," Cell, vol. 126, no. 6, pp. 1109-1120, 2006.

[62] A. Himmelbach, T. Hoffmann, M. Leube, B. Höhener, and E. Grill, "Homeodomain protein ATHB6 is a target of the protein phosphatase $\mathrm{ABI}$ and regulates hormone responses in Arabidopsis," EMBO Journal, vol. 21, no. 12, pp. 3029-3038, 2002.

[63] A.-C. Mustilli, S. Merlot, A. Vavasseur, F. Fenzi, and J. Giraudat, "Arabidopsis OST1 protein kinase mediates the regulation of stomatal aperture by abscisic acid and acts upstream of reactive oxygen species production," The Plant Cell, vol. 14, no. 12, pp. 3089-3099, 2002.

[64] J. Zhu, Z. Gong, C. Zhang et al., "OSM1/SYP61: A syntaxin protein in Arabidopsis controls abscisic acid-mediated and non-abscisic acid-mediated responses to abiotic stress," The Plant Cell, vol. 14, no. 12, pp. 3009-3028, 2002.

[65] V. Haake, D. Cook, J. L. Riechmann, O. Pineda, M. F. Thomashow, and J. Z. Zhang, "Transcription factor CBF4 is a regulator of drought adaptation in Arabidopsis," Plant Physiology, vol. 130, no. 2, pp. 639-648, 2002.

[66] H. Abe, T. Urao, T. Ito, M. Seki, K. Shinozaki, and K. YamaguchiShinozaki, "Arabidopsis AtMYC2 (bHLH) and AtMYB2 (MYB) function as transcriptional activators in abscisic acid signaling," The Plant Cell, vol. 15, no. 1, pp. 63-78, 2003.

[67] E. Hosy, A. Vavasseur, K. Mouline et al., "The Arabidopsis outward $\mathrm{K}+$ channel GORK is involved in regulation of stomatal movements and plant transpiration," Proceedings of the National Acadamy of Sciences of the United States of America, vol. 100, no. 9, pp. 5549-5554, 2003.

[68] S. Pandey and S. M. Assmann, "The Arabidopsis putative G protein-coupled receptor GCR1 interacts with the G protein $\alpha$ subunit GPA1 and regulates abscisic acid signaling," The Plant Cell, vol. 16, no. 6, pp. 1616-1632, 2004.

[69] M. Kasuga, S. Miura, K. Shinozaki, and K. YamaguchiShinozaki, "A combination of the Arabidopsis DREB1A gene and stress-inducible rd29A promoter improved drought- and low-temperature stress tolerance in tobacco by gene transfer," Plant \& Cell Physiology (PCP), vol. 45, no. 3, pp. 346-350, 2004.

[70] S. Kim, J.-Y. Yang, J. Xu, I.-C. Jang, M. J. Prigge, and N.-H. Chua, "Two cap-binding proteins CBP20 and CBP80 are involved in processing primary microRNAs," Plant \& Cell Physiology (PCP), vol. 49, no. 11, pp. 1634-1644, 2008.

[71] M. Jossier, L. Kroniewicz, F. Dalmas et al., "The Arabidopsis vacuolar anion transporter, AtCLCc, is involved in the regulation of stomatal movements and contributes to salt tolerance," The Plant Journal, vol. 64, no. 4, pp. 563-576, 2010.

[72] L.-S. P. Tran, K. Nakashima, Y. Sakuma et al., "Co-expression of the stress-inducible zinc finger homeodomain ZFHD1 and NAC transcription factors enhances expression of the ERD1 gene in Arabidopsis," The Plant Journal, vol. 49, no. 1, pp. 46-63, 2007.

[73] Y. Miao, D. Lv, P. Wang et al., "An Arabidopsis glutathione peroxidase functions as both a redox transducer and a scavenger in abscisic acid and drought stress responses," The Plant Cell, vol. 18, no. 10, pp. 2749-2766, 2006.
[74] N. Robert, S. Merlot, V. N'Guyen, A. Boisson-Dernier, and J. I. Schroeder, "A hypermorphic mutation in the protein phosphatase 2C HAB1 strongly affects ABA signaling in Arabidopsis," FEBS Letters, vol. 580, no. 19, pp. 4691-4696, 2006.

[75] S. Sridha and K. Wu, "Identification of AtHD2C as a novel regulator of abscisic acid responses in Arabidopsis," The Plant Journal, vol. 46, no. 1, pp. 124-133, 2006.

[76] M. Klein, M. Geisler, J. S. Su et al., "Disruption of AtMRP4, a guard cell plasma membrane ABCC-type ABC transporter, leads to deregulation of stomatal opening and increased drought susceptibility," The Plant Journal, vol. 39, no. 2, pp. 219236, 2004.

[77] A. Aharoni, S. Dixit, R. Jetter, E. Thoenes, G. Van Arkel, and A. Pereira, "The SHINE clade of AP2 Domain Transcription Factors Activates Wax Biosynthesis, Alters Cuticle Properties, and Confers Drought Tolerance when Overexpressed in Arabidopsis W inside a box sign," The Plant Cell, vol. 16, no. 9, pp. 2463-2480, 2004.

[78] A. Karaba, S. Dixit, R. Greco et al., "Improvement of water use efficiency in rice by expression of HARDY, an Arabidopsis drought and salt tolerance gene," Proceedings of the National Acadamy of Sciences of the United States of America, vol. 104, no. 39, pp. 15270-15275, 2007.

[79] W. Tang, Q. Ji, Y. Huang et al., "FAR-RED ELONGATED HYPOCOTYl3 and FAR-RED IMPAIRED RESPONSE1 transcription factors integrate light and abscisic acid signaling in Arabidopsis," Plant Physiology, vol. 163, no. 2, pp. 857-866, 2013.

[80] A. Peremarti, L. Bassie, P. Christou, and T. Capell, "Spermine facilitates recovery from drought but does not confer drought tolerance in transgenic rice plants expressing Datura stramonium S-adenosylmethionine decarboxylase," Plant Molecular Biology, vol. 70, no. 3, pp. 253-264, 2009.

[81] J. Zhao, Y. Gao, Z. Zhang, T. Chen, W. Guo, and T. Zhang, "A receptor-like kinase gene (GbRLK) from Gossypium barbadense enhances salinity and drought-stress tolerance in Arabidopsis," BMC Plant Biology, vol. 13, article 110, 2013.

[82] W. Lu, X. Chu, Y. Li, C. Wang, and X. Guo, "Cotton GhMKK1 Induces the Tolerance of Salt and Drought Stress, and Mediates Defence Responses to Pathogen Infection in Transgenic Nicotiana benthamiana," PLoS ONE, vol. 8, no. 7, Article ID e68503, 2013.

[83] G. Zhang, M. Chen, L. Li et al., "Overexpression of the soybean GmERF3 gene, an AP2/ERF type transcription factor for increased tolerances to salt, drought, and diseases in transgenic tobacco," Journal of Experimental Botany, vol. 60, no. 13, pp. 3781-3796, 2009.

[84] L. Tang, H. Cai, W. Ji et al., “Overexpression of GsZFP1 enhances salt and drought tolerance in transgenic alfalfa (Medicago sativa L.)," Plant Physiology and Biochemistry, vol. 71, pp. 22-30, 2013.

[85] P. E. Verslues, Y. Guo, C.-H. Dong, W. Ma, and J.-K. Zhu, "Mutation of SAD2, an importin $\beta$-domain protein in Arabidopsis, alters abscisic acid sensitivity," The Plant Journal, vol. 47, no. 5, pp. 776-787, 2006.

[86] S.-J. Oh, C.-W. Kwon, D.-W. Choi, S. I. Song, and J.-K. Kim, "Expression of barley HvCBF4 enhances tolerance to abiotic stress in transgenic rice," Plant Biotechnology Journal, vol. 5, no. 5, pp. 646-656, 2007.

[87] Y. Saijo, S. Hata, J. Kyozuka, K. Shimamoto, and K. Izui, “Overexpression of a single $\mathrm{Ca} 2+$-dependent protein kinase confers both cold and salt/drought tolerance on rice plants," The Plant Journal, vol. 23, no. 3, pp. 319-327, 2000. 
[88] Y. Xiang, Y. Huang, and L. Xiong, "Characterization of stressresponsive CIPK genes in rice for stress tolerance improvement," Plant Physiology, vol. 144, no. 3, pp. 1416-1428, 2007.

[89] W. Liu, J. C. Reif, N. Ranc, G. D. Porta, and T. Würschum, "Comparison of biometrical approaches for QTL detection in multiple segregating families," Theoretical and Applied Genetics, vol. 125, no. 5, pp. 987-998, 2012.

[90] J. A. Rafalski, "Association genetics in crop improvement," Current Opinion in Plant Biology, vol. 13, no. 2, pp. 174-180, 2010.

[91] P. Vikram, B. P. M. Swamy, S. Dixit et al., “QDTY1.1, a major QTL for rice grain yield under reproductive-stage drought stress with a consistent effect in multiple elite genetic backgrounds," BMC Genetics, vol. 12, article no. 89, 2011.

[92] C. Alonso-Blanco, M. G. M. Aarts, L. Bentsink et al., "What has natural variation taught us about plant development, physiology, and adaptation?” The Plant Cell, vol. 21, no. 7, pp. 1877-1896, 2009.

[93] K. Chenu, S. C. Chapman, F. Tardieu, G. McLean, C. Welcker, and G. L. Hammer, "Simulating the yield impacts of organlevel quantitative trait loci associated with drought response in maize: A "gene-to-phenotype" modeling approach," Genetics, vol. 183, no. 4, pp. 1507-1523, 2009.

[94] F. Tardieu and R. Tuberosa, "Dissection and modelling of abiotic stress tolerance in plants," Current Opinion in Plant Biology, vol. 13, no. 2, pp. 206-212, 2010.

[95] R. Tuberosa and S. Salvi, "Genomics-based approaches to improve drought tolerance of crops," Trends in Plant Science, vol. 11, no. 8, pp. 405-412, 2006.

[96] S. Salvi and R. Tuberosa, "Cloning QTLs in plants," GenomicsAssisted Crop Improvement, vol. 1, pp. 207-225, 2007.

[97] G. Chen, T. Komatsuda, J. F. Ma et al., "An ATP-binding cassette subfamily G full transporter is essential for the retention of leaf water in both wild barley and rice," Proceedings of the National Acadamy of Sciences of the United States of America, vol. 108, no. 30, pp. 12354-12359, 2011.

[98] D. Kliebenstein, "Quantitative genomics: analyzing intraspecific variation using global gene expression polymorphisms or eQTLs," Annual Review of Plant Biology, vol. 60, pp. 93-114, 2009.

[99] G.-P. Xue, C. L. McIntyre, S. Chapman et al., "Differential gene expression of wheat progeny with contrasting levels of transpiration efficiency," Plant Molecular Biology, vol. 61, no. 6, pp. 863-881, 2006.

[100] B. J. Hayes, P. J. Bowman, A. J. Chamberlain, and M. E. Goddard, "Erratum: Invited review: Genomic selection in dairy cattle: Progress and challenges (Journal of Dairy Science 92 (433443))," Journal of Dairy Science, vol. 92, no. 3, p. 1313, 2009.

[101] R. E. Lorenzana and R. Bernardo, "Accuracy of genotypic value predictions for marker-based selection in biparental plant populations," Theoretical and Applied Genetics, vol. 120, no. 1, pp. 151-161, 2009.

[102] J. Crossa, G. de los Campos, P. Pérez et al., "Prediction of genetic values of quantitative traits in plant breeding using pedigree and molecular markers," Genetics, vol. 186, no. 2, pp. 713-724, 2010.

[103] Y. Zhao, M. Gowda, W. Liu et al., "Accuracy of genomic selection in European maize elite breeding populations," Theoretical and Applied Genetics, vol. 124, no. 4, pp. 769-776, 2012.

[104] C. Feuillet, J. E. Leach, J. Rogers, P. S. Schnable, and K. Eversole, "Crop genome sequencing: Lessons and rationales," Trends in Plant Science, vol. 16, no. 2, pp. 77-88, 2011.
[105] R. K. Varshney, A. Graner, and M. E. Sorrells, "Genomicsassisted breeding for crop improvement," Trends in Plant Science, vol. 10, no. 12, pp. 621-630, 2005.

[106] T. Hadiarto and L.-S. P. Tran, "Progress studies of droughtresponsive genes in rice," Plant Cell Reports, vol. 30, no. 3, pp. 297-310, 2011.

[107] M. Hampton, W. W. Xu, B. W. Kram et al., "Identification of differential gene expression in Brassica rapa nectaries through expressed sequence tag analysis," PLoS ONE, vol. 5, no. 1, Article ID e8782, 2010.

[108] Q. Du, M. Zhao, W. Gao, S. Sun, and W.-X. Li, "microRNA/ microRNA* complementarity is important for the regulation pattern of NFYA5 by miR169 under dehydration shock in Arabidopsis," The Plant Journal, vol. 91, no. 1, pp. 22-33, 2017.

[109] F. R. Kulcheski, L. F. V. de Oliveira, L. G. Molina et al., "Identification of novel soybean microRNAs involved in abiotic and biotic stresses," BMC Genomics, vol. 12, article 307, 2011.

[110] P. Liang and A. B. Pardee, "Differential display of eukaryotic messenger RNA by means of the polymerase chain reaction," Science, vol. 257, no. 5072, pp. 967-971, 1992.

[111] C. W. B. Bachem, R. S. van der Hoeven, S. M. de Bruijn, D. Vreugdenhil, M. Zabeau, and R. G. F. Visser, "Visualization of differential gene expression using a novel method of RNA fingerprinting based on AFLP: analysis of gene expression during potato tuber development," The Plant Journal, vol. 9, no. 5, pp. 745-753, 1996.

[112] M. Sahebi, M. M. Hanafi, P. Azizi, A. Hakim, S. Ashkani, and R. Abiri, "Suppression Subtractive Hybridization Versus Next-Generation Sequencing in Plant Genetic Engineering: Challenges and Perspectives," Molecular Biotechnology, vol. 57, no. 10, pp. 880-903, 2015.

[113] N. Sreenivasulu, R. Sunkar, U. Wobus, and M. Strickert, "Array platforms and bioinformatics tools for the analysis of plant transcriptome in response to abiotic stress." Methods in Molecular Biology (Clifton, N.J.), vol. 639, pp. 71-93, 2010.

[114] N. L. Raju, B. N. Gnanesh, P. Lekha et al., "The first set of EST resource for gene discovery and marker development in pigeonpea (Cajanus cajan L.)," BMC Plant Biology, vol. 10, article no. $45,2010$.

[115] H. Matsumura, K. Yoshida, S. Luo et al., "High-throughput superSAGE for digital gene expression analysis of multiple samples using next generation sequencing," PLoS ONE, vol. 5, no. 8, Article ID e12010, 2010.

[116] K. L. Nielsen, A. L. Høgh, and J. Emmersen, "DeepSAGE - Digital transcriptomics with high sensitivity, simple experimental protocol and multiplexing of samples," Nucleic Acids Research, vol. 34, no. 19, article no. e133, 2006.

[117] K. L. Nielsen, A. H. Petersen, and J. Emmersen, DeepSAGE: Tagbased transcriptome analysis beyond microarrays, in Next Generation Genome Sequencing: Towards Personalized Medicine, M. Janitz, Ed., Wiley-VCH Verlag GmbH \& Co. KGaA, Weinheim, Germany, 2008.

[118] U. Nagalakshmi, Z. Wang, K. Waern et al., "The transcriptional landscape of the yeast genome defined by RNA sequencing," Science, vol. 320, no. 5881, pp. 1344-1349, 2008.

[119] J. H. Malone and B. Oliver, "Microarrays, deep sequencing and the true measure of the transcriptome," BMC Biology, vol. 9, article no. 34, 2011.

[120] P. J. Hiremath, A. Farmer, S. B. Cannon et al., "Large-scale transcriptome analysis in chickpea (Cicer arietinum L.), an orphan legume crop of the semi-arid tropics of Asia and Africa," Plant Biotechnology Journal, vol. 9, no. 8, pp. 922-931, 2011. 
[121] E. Potokina, A. Druka, Z. Luo, R. Wise, R. Waugh, and M. Kearsey, "Gene expression quantitative trait locus analysis of 16000 barley genes reveals a complex pattern of genome-wide transcriptional regulation," The Plant Journal, vol. 53, no. 1, pp. 90-101, 2008.

[122] A. Blum, "Drought resistance is it really a complex trait?" Functional Plant Biology, vol. 38, no. 10, pp. 753-757, 2011.

[123] L. M. Wakim, J. Waithman, N. van Rooijen, W. R. Heath, and F. R. Carbone, "Dendritic cell-induced memory T cell activation in nonlymphoid tissues," Science, vol. 319, no. 5860, pp. 198-202, 2008.

[124] M. A. Saddique, Z. Ali, A. S. Khan, I. A. Rana, and I. H. Shamsi, "Inoculation with the endophyte Piriformospora indica significantly affects mechanisms involved in osmotic stress in rice," Rice, vol. 11, no. 1, 2018.

[125] G. Miller, N. Suzuki, S. Ciftci-Yilmaz, and R. Mittler, "Reactive oxygen species homeostasis and signalling during drought and salinity stresses," Plant, Cell \& Environment, vol. 33, no. 4, pp. 453-467, 2010.

[126] C. A. Jaleel, P. Manivannan, A. Wahid et al., "Drought stress in plants: a review on morphological characteristics and pigments composition," International Journal of Agriculture and Biology, vol. 11, no. 1, pp. 100-105, 2009.

[127] P. Swain, M. Anumalla, S. Prusty, B. C. Marndi, and G. J. N. Rao, "Characterization of some Indian native land race rice accessions for drought tolerance at seedling stage," Australian Journal of Crop Science, vol. 8, no. 3, pp. 324-331, 2014.

[128] A. Mostajeran and V. Rahimi-Eichi, "Effects of drought stress on growth and yield of rice (Oryza sativa L.) cultivars and accumulation of proline and soluble sugars in sheath and blades of their different ages leaves," American-Eurasian Journal of Agricultural \& Environmental Science, vol. 5, pp. 264-272, 2009.

[129] M. Ashfaq, M. S. Haider, A. S. Khan, and S. U. Allah, "Breeding potential of the basmati rice germplasm under water stress condition," African Journal of Biotechnology, vol. 11, pp. 66476657, 2014.

[130] M. B. Sokoto and A. Muhammad, "Response of Rice Varieties to Water Stress in Sokoto, Sudan Savannah, Nigeria," Journal of Biosciences and Medicines, vol. 02, no. 01, pp. 68-74, 2014.

[131] M. Farooq, N. Kobayashi, O. Ito, A. Wahid, and R. Serraj, "Broader leaves result in better performance of indica rice under drought stress," Journal of Plant Physiology, vol. 167, no. 13, pp. 1066-1075, 2010.

[132] M. Usman, Z. Raheem, T. Ahsan, A. Iqbal, Z. N. Sarfaraz, and Z. Haq, "Morphological, physiological and biochemical attributes as indicators for drought tolerance in rice (Oryza sativa L)," European Journal of Biological Sciences, vol. 5, pp. 23-28, 2013.

[133] Maisura, M. Achmad Chozin, I. Lubis, A. Junaedi, and H. Ehara, "Some physiological character responses of rice under drought conditions in a paddy system," Journal of the International Society for Southeast Asian Agricultural Sciences, vol. 20, no. 1, pp. 104-114, 2014.

[134] G. Pantuwan, S. Fukai, M. Cooper, S. Rajatasereekul, and J. C. O'Toole, "Yield response of rice (Oryza sativa L.) genotypes to drought under rainfed lowlands 2. Selection of drought resistant genotypes," Field Crops Research, vol. 73, no. 2-3, pp. 169-180, 2002.

[135] T. L. B. Acuña, H. R. Lafitte, and L. J. Wade, "Genotype $\times$ environment interactions for grain yield of upland rice backcross lines in diverse hydrological environments," Field Crops Research, vol. 108, no. 2, pp. 117-125, 2008.
[136] S. Kumar, S. K. Dwivedi, S. S. Singh et al., "Morphophysiological traits associated with reproductive stage drought tolerance of rice (Oryza sativa L.) genotypes under rain-fed condition of eastern Indo-Gangetic Plain," Indian Journal of Plant Physiology, vol. 19, no. 2, pp. 87-93, 2014.

[137] R. Shahryari, E. Gurbanov, A. Gadimov, and D. Hassanpanah, "Tolerance of 42 bread wheat genotypes to drought stress after anthesis," Pakistan Journal of Biological Sciences, vol. 11, no. 10, pp. 1330-1335, 2008.

[138] M. Farooq, A. Wahid, and D.-J. Lee, "Exogenously applied polyamines increase drought tolerance of rice by improving leaf water status, photosynthesis and membrane properties," Acta Physiologiae Plantarum, vol. 31, no. 5, pp. 937-945, 2009.

[139] S. A. Anjum, X.-Y. Xie, L.-C. Wang, M. F. Saleem, C. Man, and W. Lei, "Morphological, physiological and biochemical responses of plants to drought stress," African Journal of Agricultural Research, vol. 6, no. 9, pp. 2026-2032, 2011.

[140] A. Gana, "Screening and resistance of traditional and improved cultivars of rice to drought stress at Badeggi, Niger State, Nigeria," Agriculture and Biology Journal of North America (ABJNA), vol. 2, no. 6, pp. 1027-1031, 2011.

[141] H. Nonami, "Plant water relations and control of cell elongation at low water potentials," Journal of Plant Research, vol. 111, no. 1103, pp. 373-382, 1998.

[142] M. Hussain, M. A. Malik, M. Farooq, M. Y. Ashraf, and M. A. Cheema, "Improving drought tolerance by exogenous application of glycinebetaine and salicylic acid in sunflower," Journal of Agronomy and Crop Science, vol. 194, no. 3, pp. 193199, 2008.

[143] S. Dixit, A. Singh, and A. Kumar, "Rice breeding for high grain yield under drought: A strategic solution to a complex problem," International Journal of Agronomy, vol. 2014, 2014.

[144] R. R. Mir, M. Zaman-Allah, N. Sreenivasulu, R. Trethowan, and R. K. Varshney, "Integrated genomics, physiology and breeding approaches for improving drought tolerance in crops," Theoretical and Applied Genetics, vol. 125, no. 4, pp. 625-645, 2012.

[145] J. Passioura, "The drought environment: Physical, biological and agricultural perspectives," Journal of Experimental Botany, vol. 58, no. 2, pp. 113-117, 2007.

[146] A. M. Manschadi, J. Christopher, P. Devoil, and G. L. Hammer, "The role of root architectural traits in adaptation of wheat to water-limited environments," Functional Plant Biology, vol. 33, no. 9, pp. 823-837, 2006.

[147] N. C. Collins, F. Tardieu, and R. Tuberosa, "Quantitative trait loci and crop performance under abiotic stress: where do we stand?” Plant Physiology, vol. 147, no. 2, pp. 469-486, 2008.

[148] M. Vargas, F. A. Van Eeuwijk, J. Crossa, and J.-M. Ribaut, "Mapping QTLs and QTL $x$ environment interaction for CIMMYT maize drought stress program using factorial regression and partial least squares methods," Theoretical and Applied Genetics, vol. 112, no. 6, pp. 1009-1023, 2006.

[149] M. Reynolds and R. Tuberosa, "Translational research impacting on crop productivity in drought-prone environments," Current Opinion in Plant Biology, vol. 11, no. 2, pp. 171-179, 2008.

[150] K. Yamaguchi-Shinozaki and K. Shinozaki, "Transcriptional regulatory networks in cellular responses and tolerance to dehydration and cold stresses," Annual Review of Plant Biology, vol. 57, pp. 781-803, 2006.

[151] A. Aprile, A. M. Mastrangelo, A. M. De Leonardis et al., "Transcriptional profiling in response to terminal drought 
stress reveals differential responses along the wheat genome," BMC Genomics, vol. 10, article no. 279, 2009.

[152] P. Azizi, M. Y. Rafii, M. Mahmood et al., "Differential gene expression reflects morphological characteristics and physiological processes in rice immunity against blast pathogen Magnaporthe oryzae," PLOS ONE, vol. 10, no. 5, Article ID e0126188, 2015.

[153] G.-H. He, J.-Y. Xu, Y.-X. Wang et al., "Drought-responsive WRKY transcription factor genes TaWRKY1 and TaWRKY33 from wheat confer drought and/or heat resistance in Arabidopsis," BMC Plant Biology, vol. 16, no. 1, article no. 116, 2016.

[154] L. Wang, W. Zhu, L. Fang et al., "Genome-wide identification of WRKY family genes and their response to cold stress in Vitis vinifera," BMC Plant Biology, vol. 14, no. 1, article 103, 2014.

[155] Z. Xie, Z.-L. Zhang, X. Zou et al., "Annotations and functional analyses of the rice WRKY gene superfamily reveal positive and negative regulators of abscisic acid signaling in aleurone cells," Plant Physiology, vol. 137, no. 1, pp. 176-189, 2005.

[156] T. Eulgem, P. J. Rushton, S. Robatzek, and I. E. Somssich, "The WRKY superfamily of plant transcription factors," Trends in Plant Science, vol. 5, no. 5, pp. 199-206, 2000.

[157] Q. Yuan, S. Ouyang, A. Wang et al., "The Institute for genomic research Osal rice genome annotation database," Plant Physiology, vol. 138, no. 1, pp. 18-26, 2005.

[158] T. T. Pham, P. Sripichitt, S. Chanprame, and S. Peyachoknagul, "Transfer of drought resistant character from wild rice (Oryza meridionalis and Oryza nivara) to cultivated rice (Oryza sativa L.) by backcrossing and immature embryo culture," Kasetsart Journal - Natural Science, vol. 40, no. 3, pp. 582-594, 2006.

[159] S. Juneja, A. Das, S. V. Joshi et al., "Oryza nivara (Sharma et Shastry) the progenitor of O. sativa (L.) subspecies indica harbours rich genetic diversity as measured by SSR markers," Current Science, vol. 91, no. 8, pp. 1079-1085, 2006.

[160] E. L. L. Sonnhammer, S. R. Eddy, E. Birney, A. Bateman, and R. Durbin, "Pfam: Multiple sequence alignments and HMMprofiles of protein domains," Nucleic Acids Research, vol. 26, no. 1, pp. 320-322, 1998.

[161] C. A. Ross, Y. Liu, and Q. J. Shen, "The WRKY gene family in rice (Oryza sativa)," Journal of Integrative Plant Biology, vol. 49, no. 6, pp. 827-842, 2007.

[162] C. Camacho, G. Coulouris, V. Avagyan et al., "BLAST+: architecture and applications," BMC Bioinformatics, vol. 10, article 421, 2009.

[163] A. Chakhchar, M. Haworth, C. El Modafar et al., "An assessment of genetic diversity and drought tolerance in argan tree (Argania spinosa) populations: Potential for the development of improved drought tolerance," Frontiers in Plant Science, vol. 8, 2017.

[164] M. Lauteri, M. Haworth, R. Serraj, M. C. R. Monteverdi, and M. Centritto, "Photosynthetic diffusional constraints affect yield in drought stressed rice cultivars during flowering," PLOS ONE, vol. 9, no. 9, p. e109054, 2014.

[165] A. J. Pieters and S. El Souki, "Effects of drought during grain filling on PS II activity in rice," Journal of Plant Physiology, vol. 162, no. 8, pp. 903-911, 2005.

[166] Y. Zhou, H. M. Lam, and J. Zhang, "Inhibition of photosynthesis and energy dissipation induced by water and high light stresses in rice," Journal of Experimental Botany, vol. 58, no. 5, pp. 12071217, 2007.

[167] J.-F. Gu, M. Qiu, and J.-C. Yang, "Enhanced tolerance to drought in transgenic rice plants overexpressing $\mathrm{C} 4$ photosynthesis enzymes," Crop Journal, vol. 1, no. 2, pp. 105-114, 2013.
[168] P. T. T. Ha, "Physiological responses of rice seedlings under drought stress," Journal of Scientific Research and Development, vol. 12, pp. 635-640, 2014.

[169] P.-M. Yang, Q.-C. Huang, G.-Y. Qin, S.-P. Zhao, and J.-G. Zhou, "Different drought-stress responses in photosynthesis and reactive oxygen metabolism between autotetraploid and diploid rice," Photosynthetica, vol. 52, no. 2, pp. 193-202, 2014.

[170] D. Rhodes and Y. Samaras, "Genetic control of osmoregulation in plants," Cellular and Molecular Physiology of Cell Volume Regulation, pp. 347-361, 1994.

[171] G. G. Shehab, O. K. Ahmed, and H. S. El-Beltagi, "Effects of various chemical agents for alleviation of drought stress in rice plants (Oryza sativa L.)," Notulae Botanicae Horti Agrobotanici Cluj-Napoca, vol. 38, no. 1, pp. 139-148, 2010.

[172] N. Verbruggen and C. Hermans, "Proline accumulation in plants: a review," Amino Acids, vol. 35, no. 4, pp. 753-759, 2008.

[173] A. R. Kemble and H. T. Macpherson, "Liberation of amino acids in perennial rye grass during wilting," Biochemical Journal, vol. 58, no. 1, pp. 46-49, 1954.

[174] M. S. Lum, M. M. Hanafi, and Y. M. Rafii, "Effect of drought stress on growth, proline and antioxidant enzyme activities of upland rice," Journal of Animal and Plant Sciences, vol. 24, no. 5, pp. 1487-1493, 2014.

[175] S. Hayat, Q. Hayat, M. N. Alyemeni, A. S. Wani, J. Pichtel, and A. Ahmad, "Role of proline under changing environments: a review," Plant Signaling and Behavior, vol. 7, no. 11, pp. 14561466, 2012.

[176] M. Fahramand, M. Mahmoody, A. Keykha, M. Noori, and K. Rigi, "Influence of abiotic stress on proline, photosynthetic enzymes and growth," The International Research Journal of Applied and Basic Sciences, vol. 8, pp. 257-265, 2014.

[177] M. Faize, L. Burgos, L. Faize et al., "Involvement of cytosolic ascorbate peroxidase and $\mathrm{Cu} / \mathrm{Zn}$-superoxide dismutase for improved tolerance against drought stress," Journal of Experimental Botany, vol. 62, no. 8, pp. 2599-2613, 2011.

[178] G. Noctor and C. H. Foyer, "Ascorbate and glutathione: keeping active oxygen under control," Annual Review of Plant Biology, vol. 49, pp. 249-279, 1998.

[179] F.-Z. Wang, Q.-B. Wang, S.-Y. Kwon, S.-S. Kwak, and W.A. $\mathrm{Su}$, "Enhanced drought tolerance of transgenic rice plants expressing a pea manganese superoxide dismutase," Journal of Plant Physiology, vol. 162, no. 4, pp. 465-472, 2005.

[180] D. S. Selote and R. Khanna-Chopra, "Drought-induced spikelet sterility is associated with an inefficient antioxidant defence in rice panicles," Physiologia Plantarum, vol. 121, no. 3, pp. 462-471, 2004.

[181] P. Sharma and R. S. Dubey, "Drought induces oxidative stress and enhances the activities of antioxidant enzymes in growing rice seedlings," Plant Growth Regulation, vol. 46, no. 3, pp. 209221, 2005.

[182] T. Takahashi and J.-I. Kakehi, "Polyamines: ubiquitous polycations with unique roles in growth and stress responses," Annals of Botany, vol. 105, no. 1, pp. 1-6, 2010.

[183] P. I. Calzadilla, A. Gazquez, S. J. Maiale et al., Polyamines as indicators and modulators of the abiotic stress in plants Plant adaptation to environmental change: Significance of amino acids and their derivatives, A. NA, G. SS, and G. R. Cabi, Eds., Wallingford, UK, 2014.

[184] J. Martin-Tanguy, "Metabolism and function of polyamines in plants: Recent development (new approaches)," Plant Growth Regulation, vol. 34, no. 1, pp. 135-148, 2001. 
[185] J. Yang, J. Zhang, K. Liu, Z. Wang, and L. Liu, "Involvement of polyamines in the drought resistance of rice," Journal of Experimental Botany, vol. 58, no. 6, pp. 1545-1555, 2007.

[186] G. O. Edmeades, G. S. McMaster, J. W. White, and H. Campos, "Genomics and the physiologist: Bridging the gap between genes and crop response," Field Crops Research, vol. 90, no. 1, pp. 5-18, 2004. 


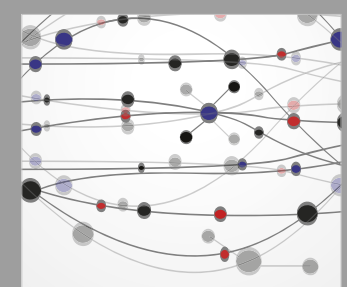

The Scientific World Journal
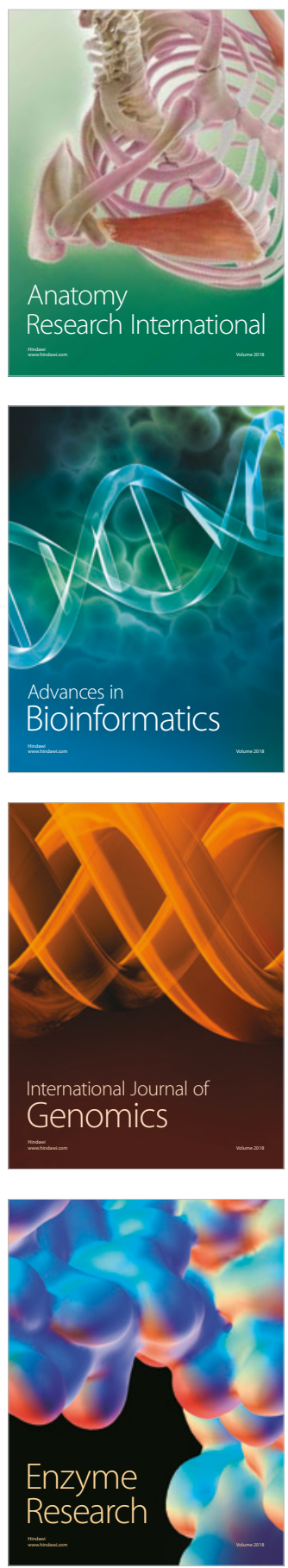
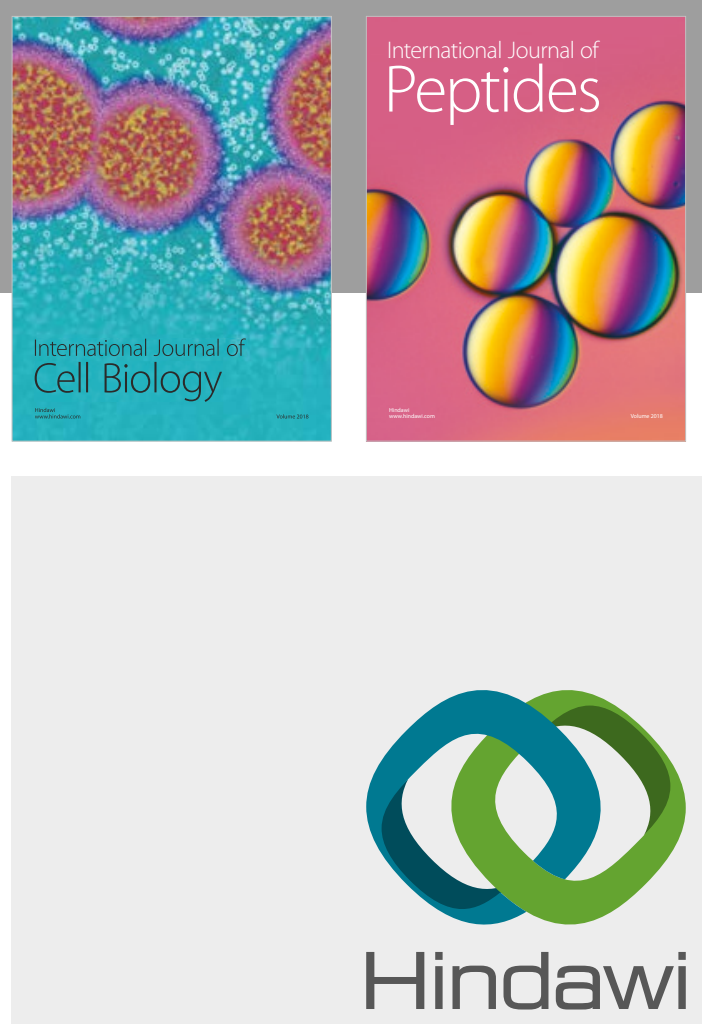

Submit your manuscripts at

www.hindawi.com
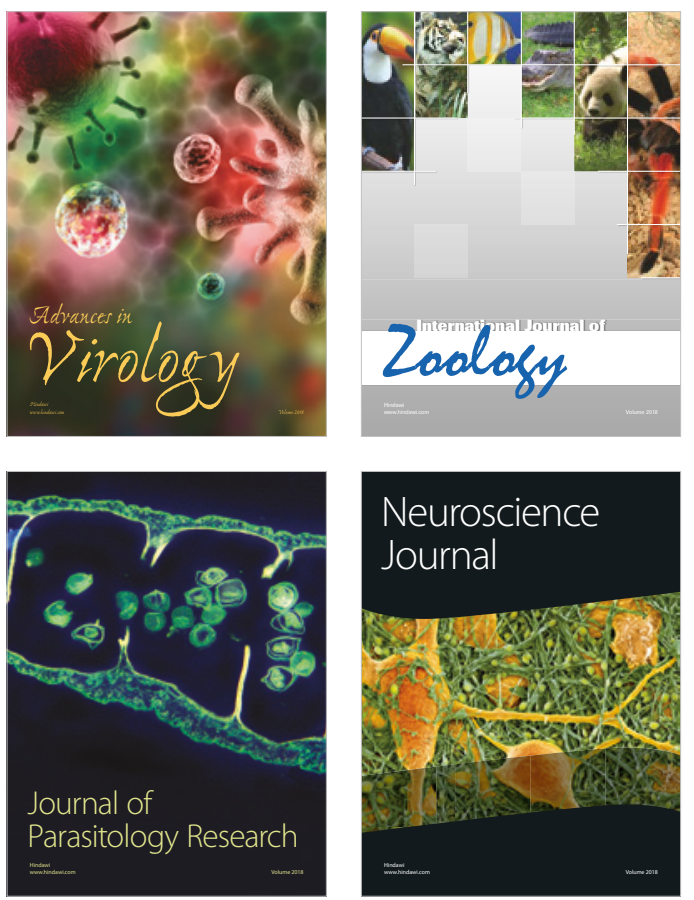
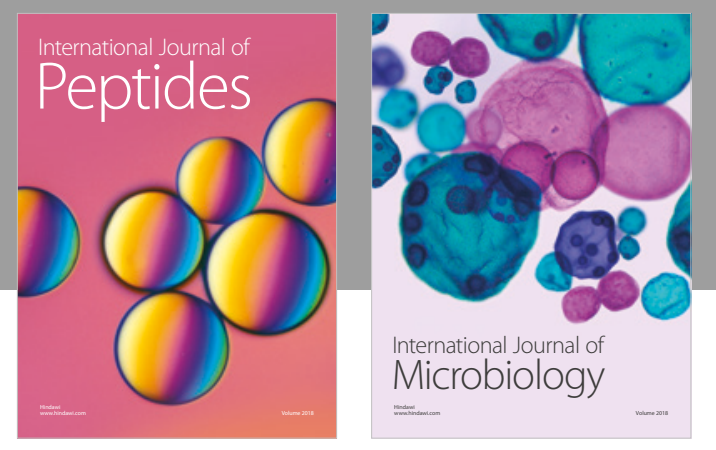

nternational Journal of Microbiology
Journal of
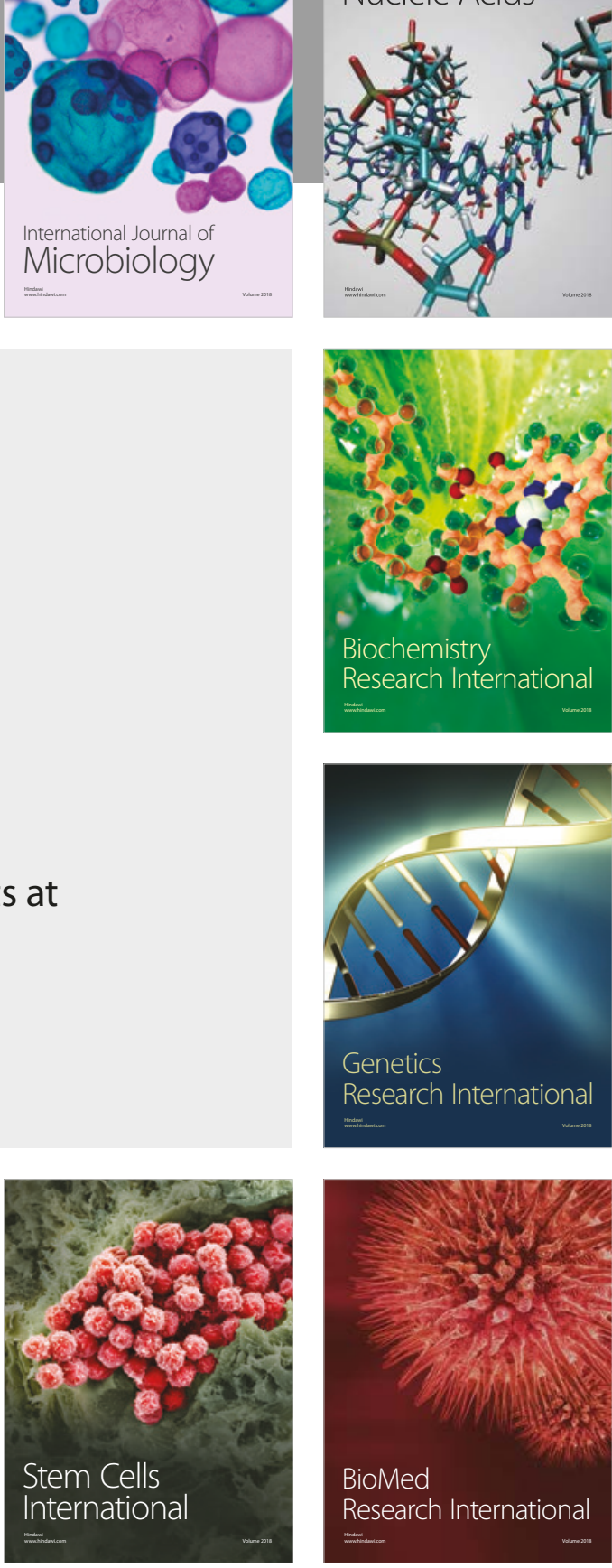
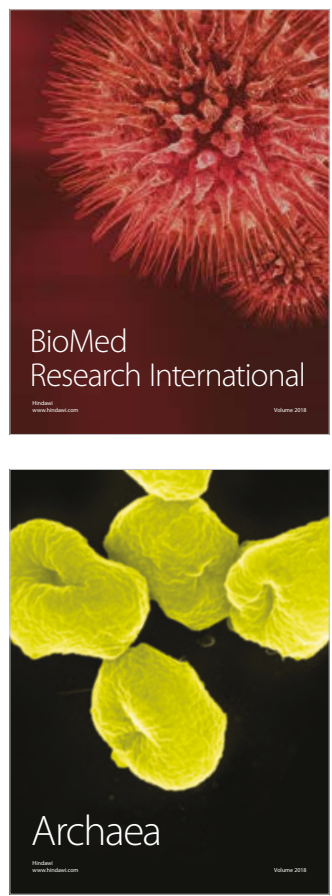